\title{
ASSESSMENT OF MODELLING NEEDS FOR SAFETY ANALYSIS OF CURRENT HTGR CONCEPTS
}

P.G. Kroeger and G.J. Van Tuyle

NUREG/CR--4434

TI86 004957

Manuscript Completed - September 1985

Date Published: December 1985

DEPARTMENT OF NUCLEAR ENERGY

BROOKHAVEN NATIONAL LABORATORY

UPTON, LONG ISLAND, NEW YORK 11973 


\section{DISCLAIMER}

This report was prepared as an account of work sponsored by an agency of the United States Government. Neither the United States Government nor any agency Thereof, nor any of their employees, makes any warranty, express or implied, or assumes any legal liability or responsibility for the accuracy, completeness, or usefulness of any information, apparatus, product, or process disclosed, or represents that its use would not infringe privately owned rights. Reference herein to any specific commercial product, process, or service by trade name, trademark, manufacturer, or otherwise does not necessarily constitute or imply its endorsement, recommendation, or favoring by the United States Government or any agency thereof. The views and opinions of authors expressed herein do not necessarily state or reflect those of the United States Government or any agency thereof. 


\section{DISCLAIMER}

Portions of this document may be illegible in electronic image products. Images are produced from the best available original document. 


\section{NOTICE}

This report was prepared as an account of work sponsored by an agency of the United States Government Neither the United States Government nor any agencv thereof, or any of their employees makes any warranty expressed or implied, or assumes any legal hability or responsibility for any third party's use or the results of such use of any information, apparatus, product or process disclosed in this report, or represents that its use by such third party would not infninge privately owned rights

The views expressed in this report are not necessarily those of the US Nuclear Regulatory Commission

Avalable from

Superintendent of Documents

U S Government Printing Office

P O Box 37082

Washıngton, DC 200137982

and

National Technical Information Service

Springfield, Vırgınıa 22161 
In view of the recent shift in emphasis of the DOE/Industry HTGR development efforts to smaller modular designs it became necessary to review the modelling needs and the codes available to assess the safety performance of these new designs.

This report provides a final assessment of the most urgent modelifing needs, comparing these to the tools avallable, and outlining the most significant areas where further modelling is required. Plans to implement the required work are presented. 

Abstract $\ldots \ldots \ldots \ldots \ldots \ldots \ldots \ldots \ldots \ldots \ldots \ldots \ldots \ldots \ldots \ldots \ldots \ldots \ldots \ldots \ldots \ldots \ldots \ldots \ldots \ldots \ldots \ldots$

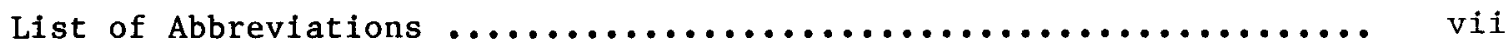

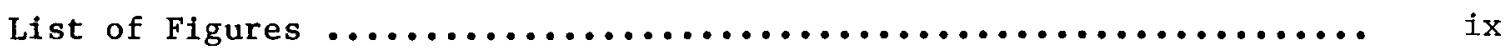

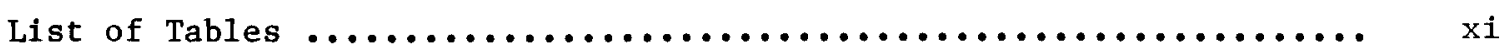

Acknowledgement $\ldots \ldots \ldots \ldots \ldots \ldots \ldots \ldots \ldots \ldots \ldots \ldots \ldots \ldots \ldots \ldots \ldots \ldots \ldots \ldots \ldots \ldots \ldots \ldots \ldots \ldots$

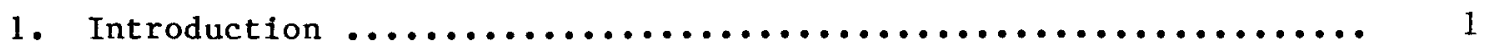

2. Comparison of Current Concepts with Previous Designs ..........

3. Accident Scenarios ................................... 4

3.1 Depressurized Core Heatup Without Forced Cooling .......... 4

3.1.1 Typical Depressurized Core Heatup Scenario With Passive RCCS ........................ 5

3.1.2 Typical Depressurized Core Heatup Scenario Without Functioning $\operatorname{RCCS} \ldots \ldots \ldots \ldots \ldots \ldots \ldots \ldots \ldots \ldots$

3.1.3 Evaluation of Analysis Tools ................... 10

3.2 NSSS Transients with Convective Heat Removal ............ 13

3.2.1 Transient with Scram ........................ 17

3.2.2 Transients Without Scram (ATWS) .................. 19

3.3 Ingress Accidents ............................... 39

3.3.1 Typical Water Ingress Scenarios .................. 39

3.3.2 Typical Air Ingress Scenarios .................. 40

3.3.3 Modelling Needs for Accidents with Significant Graphite oxidation ..................... 40

3.3.4 Available Tools for Accidents with Significant Graphite Oxidation ....................... 40

$3.3 .4 .1 \quad$ oxIDE $-3 \ldots \ldots \ldots \ldots \ldots \ldots \ldots \ldots \ldots \ldots \ldots \ldots \ldots \ldots \ldots$

$3.3 .4 .2 \quad$ REACT/THERMIX ...................... 42 
3.3.5 Comparison of OXIDE-3 and REACT/THERMIX ......... 44

3.3.6 Reactivity Transients ..................... 47

3.3.7 Secondary Side Excape of Primary Coolant .......... 48

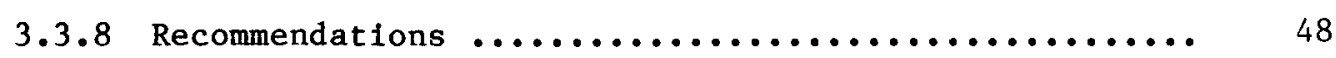

3.4 Containment/Confinement Atmosphere ................. 49

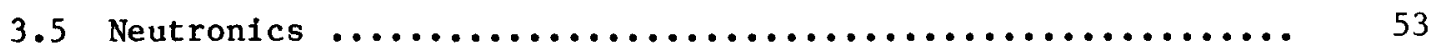

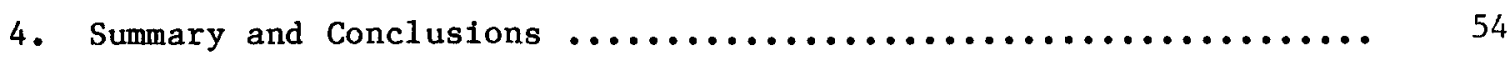

4.1 Depressurized Core Heatup Scenarios ................. 54

4.2 NSSS Transients with Convective Heat Removal ........... 55

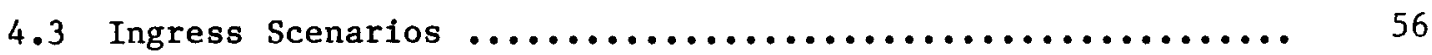

4.4 Containment/Confinement Atmosphere $\ldots \ldots \ldots \ldots \ldots \ldots \ldots \ldots \ldots$

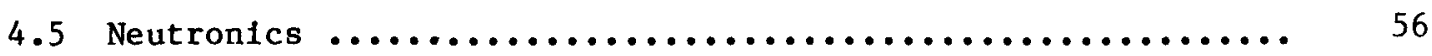

$\begin{array}{ll}\text { References } & 57\end{array}$ 
ATWS Anticipated Transient Without Scram

CACS Core Auxiliary Cooling System

DBDA Design Basis Depressurization Accident

FP Fission Product

GA GA Technologies, Inc.

KFA Kernforschungsanlage Jue1ich (Nuclear Research Institute)

LCS Lines Cooling System

LMFBR Liquid Metal Fast Breeder Reactor

LOFC Loss of Forced Circulaton

LOHS Loss of Heat Sink

LWR Light Water Reactor

NSSS Nuc1ear Steam Supply System

PPS Plant Protection System

RB Reactor Building (Containment or Confinement Type)

RC Reactor Cavity (containment or confinement type)

RCCS Reactor Cavity Cooling System

SBS Side-by-Side

STG Steam Generator

VIL Vertical-in-Line 
3.1.1 Reactor Temperatures and Heat Flows During Depressurized Core Heatup Transient With RCCS Functioning in the Passive Mode

3.1.2 Gas Content in Lower Port of Reactor Vessel and Confinement During Depressurized Core Heatup Transient with RCCS and Fraction of Core Exceeding $1600 \mathrm{C}$ During Transient

3.1.3 Reactor Temperatures and Heat Flows for Core Heatup Transient Without Operating Reactor Cavity Cooling System

3.2.1 Representation of VIL Modular HTGR System Used in Section 3.2 ATWS Analysis

3.2.2 Case 1 Primay Loop (Helium) Mass Flow Rate and Feedwater Mass Flow Rate

3.2.3 Case 1 Helium Temperatures at the Reactor Outlet and the Circulator Inlet (Steam Generator Outlet)

3.2.4 Case 1 Power Generated in the Core (Fuel Pebbles) and Power Transferred from Helium in Steam Generator

3.2.5 Case 1 Core Average Temperatures for the Fuel and Modulator Pebbles

3.2.6 Case 2 Primay Loop (Hellum) Mass Flow Rate and Feedwater Mass Flow Rate

3.2.7 Case 2 Helium Temperatures at the Reactor Outlet and the Circulator Inlet (Steam Generator Outlet)

3.2.8 Case 2 Power Generated in the Core (Fuel Pebbles) and Power Transferred from Helium in Steam Generator

3.2.9 Case 2 Core Average Temperatures for the Fuel and Modulator Pebbles

3.2.10 Case 3 Primay Loop (Helium) Mass Flow Rate and Feedwater Mass Flow Rate

3.2.11 Case 3 Helium Temperatures at the Reactor Outlet and the Circulator Inlet (Steam Generator Outlet)

3.2.12 Case 3 Power Generated in the Core (Fuel Pebbles) and Power Transferred from Helium in Steam Generator

3.2.13 Case 3 Core Average Temperatures for the Fuel and Modulator Pebbles 


\section{LIST OF FIGURES}

Figure

Title

Page

3.2.14 Case 4 Primay Loop (Helium) Mass Flow Rate and Feedwater Mass Flow Rate

3.2.15 Case 4 Helium Temperatures at the Reactor Outlet and the Circulator Inlet (Steam Generator Outlet)

3.2.16 Case 4 Power Generated in the Core (Fuel Pebbles) and Power Transferred from Helium in Steam Generator

3.2.17 Case 4 Core Average Temperatures for the Fuel and Modulator Pebbles 
LIST OF TABLES

Table

Title

Page

$2-1$

Current DOE/Industry Concepts

2

$3.1-1$

Comparison of Depressurized Core Heatup Codes

11

$3.2-1$

Codes for Section 3.2

14

$3.2-2$

Analyzing Section 3.2 Events

18

3.3 .1

Comparison of Ingress Accident Codes OXIDE-3 and REACT/THERMIX

45

$3.4-1$

Comparison of Containment Atmosphere Models

50 
A draft version of this report was reviewed by Drs. Sidney Ball and John Cleveland, and Mr. Michael Harrington of the Oak Ridge National Laboratory. Their comments and suggestions were very helpful, particularly with regard to codes developed at ORNL.

Dr. James G. Guppy of BNL reviewed and edited this report, and provided a great deal of useful input and feedback. The typing and other preparations of the document was performed by Mrs. Carmen Falkenbach. 


\section{INTRODUCTION}

With the recent shift in emphasis in the DOE/industry HTGR program for gas cooled reactors towards smaller concepts, an evaluation has to be made as to how this change will affect the accident scenarios to be considered for 1icensing purposes, and how far the currently available analysis tools can serve for this purpose. This letter report is intended to provide an initial assessment in this area.

The concepts currently under closer consideration are two modular steel vessel designs, using pebble bed fuel, as well as two PCRV designs with prismatic fuel. The departure from the previous U.S. concepts is much more significant for the two modular concepts than it is for the PCRV designs. Therefore, more attention will be focussed on the accidents to be considered and the tools required for the analysis of such modular pebble bed reactors.

This report is preliminary at this time. It intends to give most weight to those areas that we anticipate to become important early in the licensing process. It will be extended and modified later, as the evolution of the program may require.

While process heat applications as well as combined power and process heat applications have received some attention at times, such systems have not been included here at this time.

It should be noted that the manpower estimates given in this report are preliminary, and might require revision after further discussion with and directions from the NRC. 
Some of the major features of the concepts currently under consideration in the DOE/industry program are summarized in Table 2-1 $[1,2,3]$. These include 2 modular units of $250 \mathrm{MW}_{\text {th }}$, using a steel vessel and pebble bed fuel. One of these concepts is a vertical-in-line (VIL) arrangement, with the steam generator on top of the core. The other is a side-by-side arrangement (SBS), with core and steam generator in separate vessels.

Table 2-1 Current DOE/Industry Concepts

\begin{tabular}{|c|c|c|c|c|}
\hline & $\begin{array}{l}\text { Modular } \\
\quad \text { VIL }\end{array}$ & $\begin{array}{l}\text { Modular } \\
\text { SBS }\end{array}$ & $\begin{array}{l}\text { PCRV } \\
1260\end{array}$ & $\begin{array}{l}\text { PCRV } \\
1170\end{array}$ \\
\hline Core Thermal Power [MW] & 250 & 250 & 1260 & 1170 \\
\hline Core Geometry & pebble bed & pebble bed & $\begin{array}{l}\text { annular } \\
\text { prismatic }\end{array}$ & $\begin{array}{l}\text { cylindrical } \\
\text { prismatic }\end{array}$ \\
\hline Power Density [W/cc] & 3.8 & 3.8 & 3.9 & 5.8 \\
\hline Core Pressure [bar] & 87 & 72 & 72 & 72 \\
\hline Core Outlet Temperature $[\mathrm{C}]$ & 700 & 700 & 690 & 690 \\
\hline $\begin{array}{l}\text { Number of Main Cooling } \\
\text { Loops }\end{array}$ & 1 & 1 & 4 & 2 \\
\hline $\begin{array}{l}\text { Number of Forced CACS } \\
\text { Loops }\end{array}$ & 1 & 1 & 1 & 2 \\
\hline $\begin{array}{l}\text { Number of Natural Circula- } \\
\text { tion CACS Loops }\end{array}$ & (to $\begin{array}{l}1 \\
\text { RCCS) }\end{array}$ & & 1 & 1 \\
\hline $\begin{array}{l}\text { Depressurized } \\
\text { Decay Heat Removal } \\
\text { w/o Forced Circulation }\end{array}$ & $\begin{array}{l}\text { passive } \\
\text { to RCCS }\end{array}$ & $\begin{array}{l}\text { - passive } \\
\text { to RCCS }\end{array}$ & $\begin{array}{l}\text { to PCRV } \\
\text { LCS }\end{array}$ & $\begin{array}{l}\text { - to PCRV } \\
\text { LCS }\end{array}$ \\
\hline $\begin{array}{l}\text { Predicted Maximum } \\
\text { Accident Fuel } \\
\text { Temperature [C] }\end{array}$ & 1600 & 1600 & 1600 & 2900 \\
\hline
\end{tabular}

The major differences between these modular designs and previous U.S. concepts are:

- $\quad$ small size and low power density

- pebble bed fuel 
- steel vessel(s) replacing PCRV

- decay heat rejection via vessel to a passive cavity cooling system

- no auxiliary core cooling system (most concepts).

The two remaining concepts are PCRV design with prismatic fuel. They are, thus, much more closely related to the previous U.S. concepts.

The $1170 \mathrm{MW}$ concept can be considered as a scaled down version of the 2240 Base Line zêro concept. It has the same power density as the 2240 design $(5.8 \mathrm{~W} / \mathrm{cc})$. It includes a passive natural circulation loop as part of the CACS, and an enhanced liner cooling system.

The $1260 \mathrm{MW}$ PCRV concept uses an annular core of only $3.9 \mathrm{~W} / \mathrm{cc}$ power density. It also includes a passive CACS loop and an enhanced liner cooling system.

Currently, the modular concepts appear to be leading in consideration, and a shift to this design would entail a more substantial adjustment in the required licensing tools. Therefore, this report gives more attention to modular concepts than to PCRV concepts.

Apparently, the DOE effort will submit a design with a vented confinement building, rather than a pressurized containment building [1,2], and it is anticipated that early licensing work in this area will be required. For bothmodular concepts, an underground cavity rather than an above ground building has been considered, generally referred to as a reactor cavity ( $R C$ ). For simplicity and without prejudice as to the final design of the reactor building, the word "reactor building" ( $R B$ ) shall be used in this report for any kind of reactor building, be it pressurized or vented, above or below ground. 


\section{ACCIDENT SCENARIOS}

In the modular concepts a major mode of heat removal under potential accident conditions is heat rejection after depressurization and without any electrical power by conduction and radiation through the reactor vessel to the passive RCCS. The frequency of such cooldown has been estimated as $10^{-3} / \mathrm{yr}$ [4]. The next, more severe accident scenario would include faflure of the passive RCCS, which was estimated to have a frequency of $3 \times 10^{-} / \mathrm{yr}$. It appears that most major FP releases to the environment would have to include either one of these scenarios, possibly initiated by other accidents. It is not clear at this time which scenarios will be considered as DBAs and which will be considered to be severe accidents. But since the depressurized core heatup will apparently be the accident leading to most major FP releases, it was decided to consider this accident and the resulting long term RB atmosphere transient as a separate major section (Section 3.1).

Thereafter, transients with convective heat removal, including ATWS scenarios will be considered, to be followed by a section on ingress accidents. Finally, contalnment/confinement atmosphere short term transients and neutronics will be considered in separate sections.

\subsection{Depressurized Core Heating Without Forced Cooling}

The accident scenarios of this section consider a depressurization with scram and loss of all forced circulation. As pointed out above, most accident scenarios leading to any significant FP releases will include such depressurized core heatup. These accidents will be of particular importance in designs with a confinement rather than a containment, since in those designs the reactor vessel (or the PCRV liner) represents the last absolute barrier for FP releases. "Absolute" here is used in the sense that a confinement ventilation and cleanup system can only prevent releases during relatively slow blowdown events. Possible initiating events for such an accident could be extended station blackouts.

The core heatup analysis of these events is relatively straightforward. At the low gas densities after depressurization convective decay heat removal becomes negligible, while radiation gains in importance as component temperatures rise.

Due to their lower power densities and due to their smaller core sizes, all current designs, particularly the modular ones, will encounter significantly lower fuel temperatures than previous designs.

In the modular design most of the decay heat is transported by conduction and radiation through the side reflectors and the steel vessel to the passive RCCS system.

Al1 current modular concepts use such a passive RCCS system, usually with two completely independent trains, each with a cooling water storage reservoir for eight days of decay heat removal. With power available, heat removal is via air blast heat exchangers. In case of station blackout, the cooling water will boil with steam being vented to the environment and reservoir water resupplying the RCCS. 
In the modular designs, to accommodate this mode of decay heat rejection, no thermal barrier is provided. This results in a heat loss to the RCCS during normal full power operation of about $1 \mathrm{MW}$. The decay heat amounts to $2 \mathrm{MW}$ at about 10 hours. Thus, the accident load of the RCCS is not significantly higher than its normal operating load, and temperature in the vessel and RCCS area do not rise significantly above their normal levels. The core itself is expected to reach maximum fuel temperatures between 1600 and $1900 \mathrm{C}$, depending on details of the design, with most recent designs remaining around $1600 \mathrm{C}$ maximum fuel temperature. At these temperatures typical pebble bed fuel does not appear to experience any appreciable rise in fission product release $[5,6]$.

\subsubsection{Typical Depressurized Core Heatup Scenario with Passive RCCS}

Based on the design of Reference 2, we applied the THATCH code to evaluate some typical depressurized core heatup transients. Our analysis was of a scoping nature, involving several assumptions, for instance, on material properties and power peaking, where detailed information was not avallable at the time. The purpose of these computations was not to simulate highly quantitatively accurate accident transients, but to establish what approximate effects would have to be expected and what modelling tools would be required. It should also be noted that the design of Reference 2 was one of the more recent ones with a higher than usual peak fuel temperature.

Typical system temperatures and heat flows are shown in Figure 3.1.1 for a depressurized core heatup with the RCCS functioning in the passive mode. The maximum core temperature is seen to peak at 50 hours at about $1820 \mathrm{C}$. The heat transferred out of the core exceeds the decay heat after about 60 hours, and at about 85 hours the heat flow out of the vessel exceeds the decay heat, resulting in a slow system cooldown.

While in the temperature range of 1600 to $1800 \mathrm{C}$ some of the cesium might be released from the fuel [5], only a small fraction of the core reaches that temperature level.

The more significant question for this scenario is the question of net gas escape from the core to the $R B$ and from the $R B$ to the environment for a confinement type RB.

The releases of primary interest are

1. during blowdown, and

2. during the period from 20 to 100 hours when the highest core temperatures prevail and some fission products may be released.

During the initial blowdown from 70 bar to atmospheric pressure, about 340 $\mathrm{kg}$ mol of helium will be released from the core. About the same amount in the form of a helium/air mixture, carrying some of the circulating inventory, will reach the environment.

The gas contained after blowdown in various parts of the lower vessel for this sample application is shown in Figure 3.1.2. While the active core undergoes a heatup and loses some gas, the lower plenum, which is the largest 
CORE TEMPERATURES

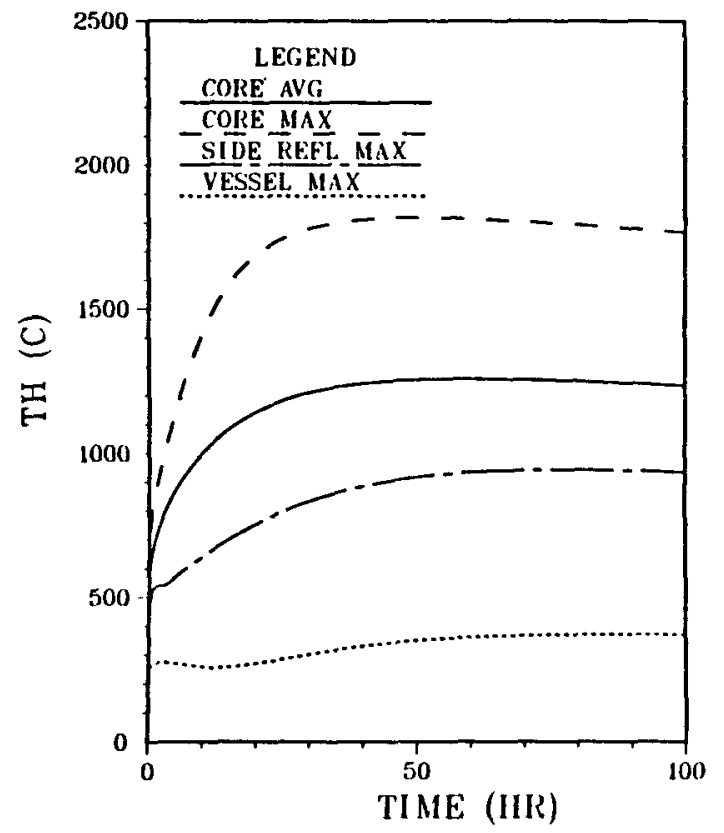

HEAT FLOW

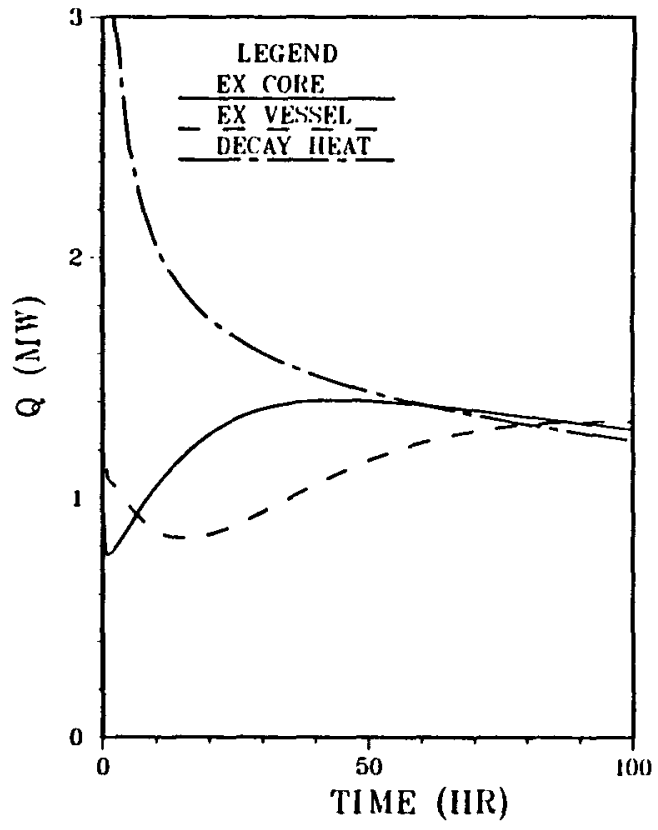

Figure 3.1.1 Reactor Temperatures and Heat Flows during Depressurized Core Heatup Transient With RCCS Functioning in the Passive Mode 
GAS IN LOWER VESSEL
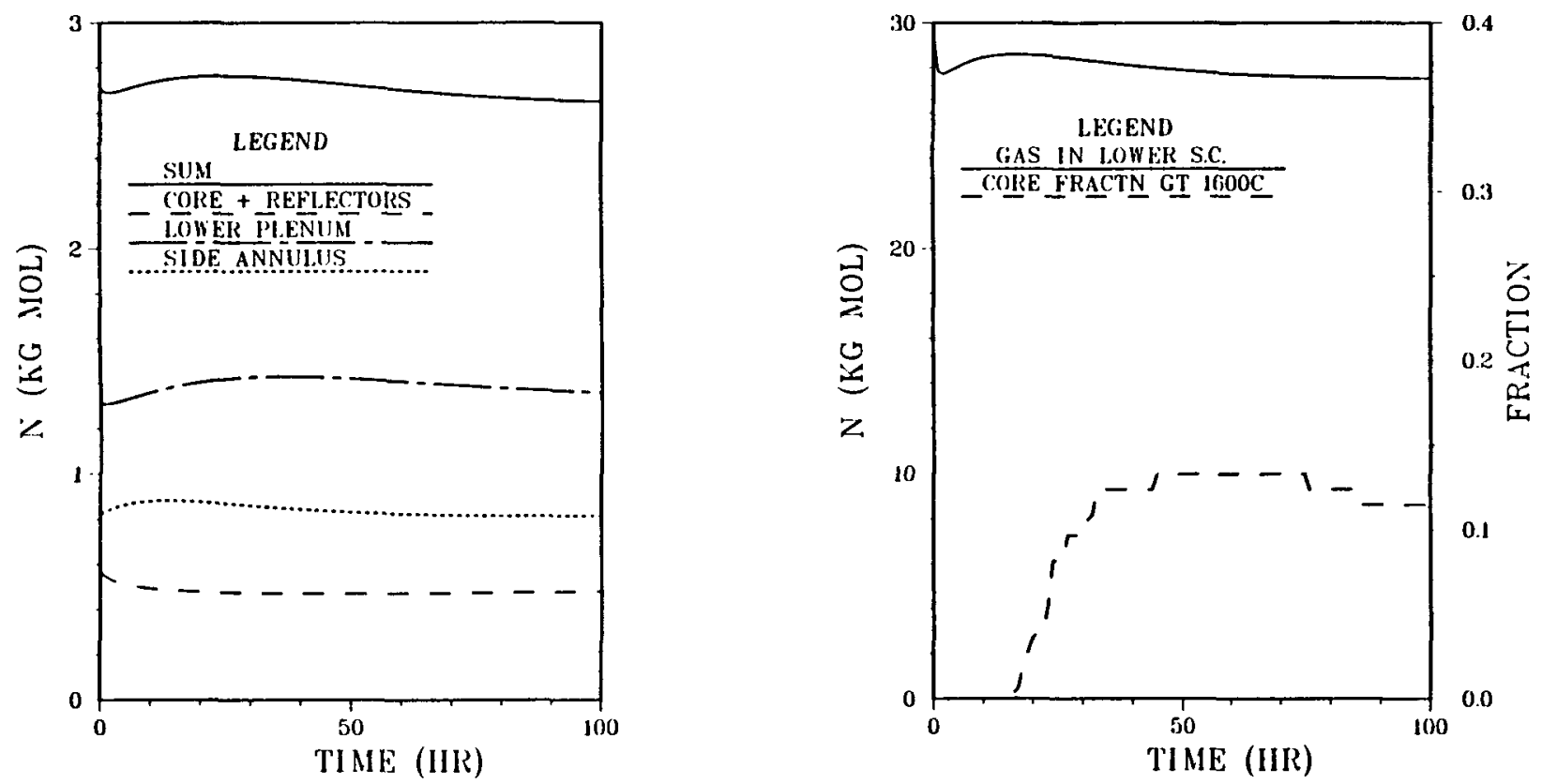

Figure 3.1.2 Gas Content in Lower Port of Reactor Vessel and Confinement During Depressurized Core Heatup Transient with RCCS and Fraction of Core Exceeding 1600 C During Transient 
gas volume, cools off slightly and can accommodate slightly more gas, such that the total lower vessel gas inventory hardly changes. Including a slight cooldown in the upper parts of the vessel, there is a net outflow of about. 1 $\mathrm{kg}$ mol or $2 \%$ of its total gas volume for the period from 20 to 100 hours. Similarly, there is a net outflow of about $1.2 \mathrm{~kg}$ mol or $1.5 \%$ of the gas volume from the RC to the environment. While these computations are of a scoping nature, and preliminary, they indicate that the net gas release to the environment during such depressurized core heatup accidents with passive RCCS can be expected to be very minor.

\subsubsection{Typical Depressurized Core Heatup Scenario Without Functioning RCCS}

While the passive operating mode of the RCCS and the typical use of two parallel independent cooling systems makes an RCCS failure highly unlikely, its potential consequences are being considered here.

Our scoping analysis was therefore applied to such a transient, and typical results are shown in Figure 3.1.3. The maximum core temperature again peaks at about $1830 \mathrm{C}$ at about 50 hours, similar to the case with RCCS. The average core temperature is also not very much higher than in the case with RCCS. About $16 \%$ of the core will exceed a temperature of $1600 \mathrm{C}$ at 60 hours, versus $14 \%$ at 50 hours in the case with RCCS.

However, the ultimate heat rejection now goes into the cavity concrete and the surrounding soil, which are typically media of low thermal diffusivity. Therefore, the metal components, and in particular the reactor vessel, are being exposed to excessive temperatures. After 100 hours, the highest vesse1 temperatures reach about $800 \mathrm{C}$, but they keep rising and reach about $1200 \mathrm{C}$ at 400 hours. If the accident transient cannot be terminated by supplying means for decay heat removal, it must be expected that physical vessel failure will result beyond 100 hours. The side cavity cooling panels and the cavity concrete will also begin to deteriorate, with concrete surface temperature reaching $600 \mathrm{C}$ at 90 hours and exceeding $900 \mathrm{C}$ at 200 hours. These results were obtained for typical concrete and soil properties (thermal diffusivity, $\left.\alpha \approx 10^{-6} \mathrm{~m}^{2} / \mathrm{s}^{*}\right)$. Assuming a higher conductivity soil $\left(\alpha \approx 2 \times 10^{-6}\right.$ $\left.\mathrm{m}^{2} / \mathrm{s}^{*}\right)$, about $200 \mathrm{C}$ lower vessel temperatures were observed.

While these computations are of a scoping nature, with some of our mode1ling not as prectse as it could have been, the results show that serious physical damage might have to be expected in cases of depressurized core heatup accidents without RCCS, and that more detailed analyses should be conducted if such sequences are to be considered as part of the licensing process.

During core heatup scenarios without RCCS, gas releases from the reactor vessel to the RC would also be more significant, amounting to about $35 \%$ of the depressurized core gas inventory, up to 400 hours. However, the gas releases due to concrete heatup from the $\mathrm{RC}$ to the environment would be expected to dominate the scenario. In contrast to PCRV designs, these gases could not react with the core graphite as long as vessel integrity is maintained.

\footnotetext{
*Guide value only, actual properties used are a function of temperature.
} 
CORE TEMPERATURES

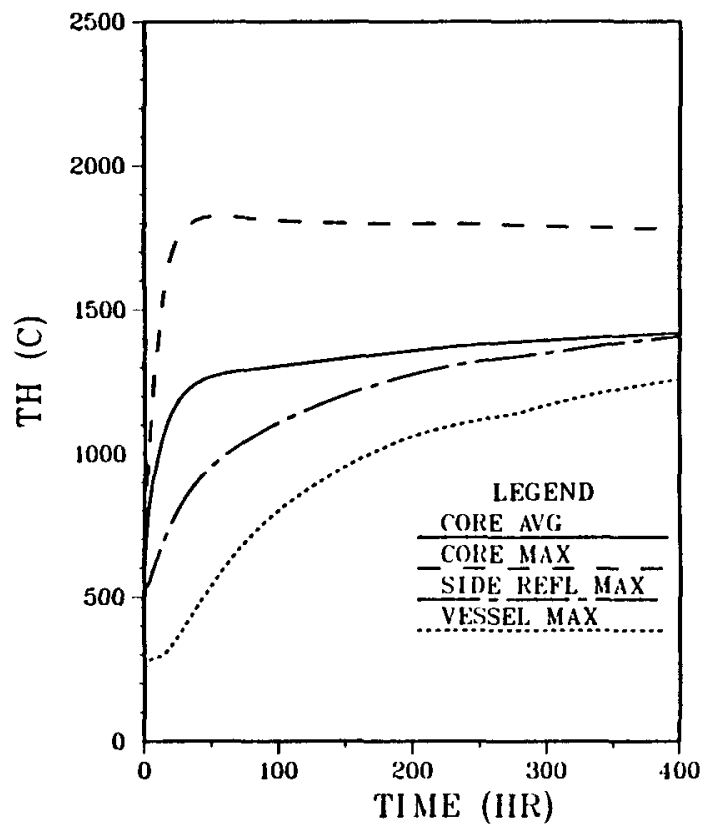

IIEAT FLOW

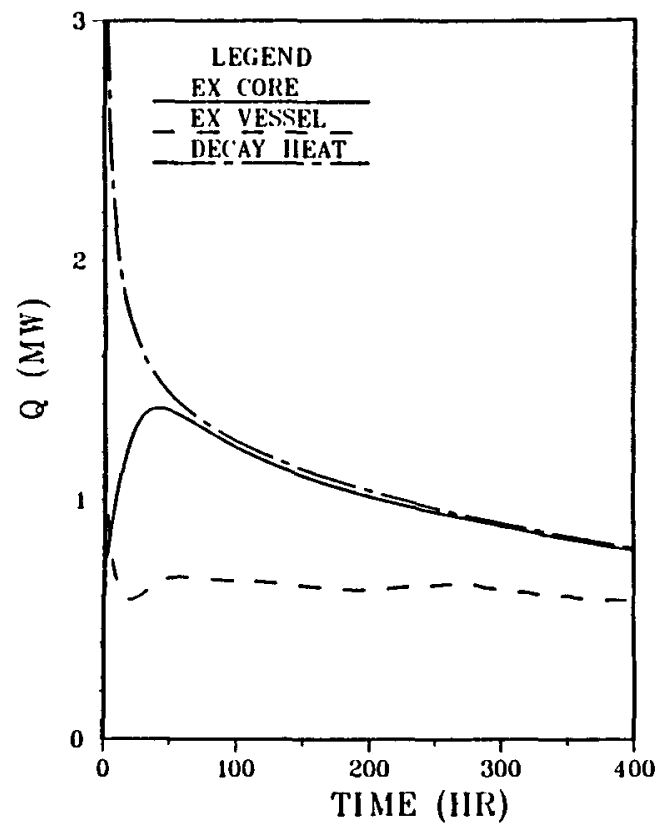

Figure 3.1.3 Reactor Temperatures and Heat Flows for Core Heatup Transient without Operating Reactor Cavity Cooling System 
To avoid the scenario outlined here, an emergency type heat sink which could remove about $1 \mathrm{MW}$ would have to be provided within the first 100 hours of the accident.

Again, the purpose of the above computations was not to establish an accurate peak vessel temperature, but to determine whether major failures, even for cases without RCCS, can possibly be ruled out. The conclusion is that major damage is not impossible, requiring either more detailed analyses or design changes, eliminating such accidents from consideration.

\subsubsection{Evaluation of Analysis Tools}

\section{Core Heatup}

The depressurized core heatup requires modelling of a typically 2-dimensional configuration of core, reflectors, plena and other components, with decay heat generation in the active core and conduction and radiation through the components to a heat sink.

The codes specifically developed for such applications are CORCON (GA) and THATCH (BNL). Also applicable for such accidents are codes 1ike Thermix for pebble bed reactors and ORECA for prismatic fuel.

CORCON and THATCH are rather general in that the user can specify any desired configuration of blocks of different materials, connected by plena or gaps with or without thermal resistances at the internal or external boundaries. The failure of certain nodes at specific prescribed temperature levels can be simulated, with either a removal of the node when it reaches the failure temperature, or its redepositing in a "dropped location," or by it changing thermal properties at failure time.

THATCH also permits the quasi-steady modelling of nodes of small thermal capacitance, thus avoiding reduced time step requirements of such small nodes.

Some of the most important features of the various codes are compared in Table 3.1-1.

As the THATCH code can handle all anticipated needs for depressurized core heatup accident modelling, we do not see any significant further modelling needs. There may be some need for better material property data, 1ike graphite conductivities under irradiated conditions, but if so, these can only be effectively addressed once specific material specifications and design details are known.

At the accident temperature levels of modular (or small PCRV) reactors not much fission product release is expected, and only very 11 tele gas exchange between reactor vessel and $R B$ is expected. For any fission product transfer out of the core, the gas flow field would be required. As the ORECA and THERMIX codes were developed for cases including convection heat transfer, they compute the flow as an integral part of the analysis. In ORECA it is axlal only (i.e., no cross-flow), but flow rates vary between refueling regions. THERMIX computes a full two-dimensional flow field. 
Table 3.1-1 Comparison of Depressurized Core Heatup Codes

\begin{tabular}{|c|c|c|c|c|}
\hline & THATCH & CORCON & ORECA & THERMIX \\
\hline Geometry & $\begin{array}{l}\text { any } \\
r-z\end{array}$ & $\begin{array}{l}\text { any } \\
r-z\end{array}$ & $\begin{array}{c}\text { prismatic } \\
\text { fuel } \\
\text { (hexagonal) }\end{array}$ & $\begin{array}{l}\text { pebble } \\
\text { bed } \\
\text { core }\end{array}$ \\
\hline Dimensional & $2-d$ & $2-d$ & $3-d$ & $2-d$ \\
\hline $\begin{array}{l}\text { General Description of } \\
\text { Configuration Via } \\
\text { Input Data }\end{array}$ & yes & yes & no & yes \\
\hline Nodalization & $\begin{array}{c}\text { user } \\
\text { option }\end{array}$ & $\begin{array}{c}\text { user } \\
\text { option }\end{array}$ & $\begin{array}{l}\text { per } \\
\text { refueling } \\
\text { region }\end{array}$ & $\begin{array}{l}\text { user } \\
\text { option }\end{array}$ \\
\hline 2-d P1ena Radiation & yes & yes & yes & no \\
\hline Material Failures & yes & yes & (yes) & (no) \\
\hline Quasi Static Layers & yes & no & no & no \\
\hline Gas F1ow & $\begin{array}{l}1-d \\
\text { separate } \\
\text { module }\end{array}$ & -- & $\begin{array}{c}1-d \\
\text { integral }\end{array}$ & $\begin{array}{c}2-d \\
\text { integral }\end{array}$ \\
\hline
\end{tabular}

As there is no measurable feedback from the flow field to the temperature field in depressurized core heatup scenarios, the THATCH code permits the computation of flow rates in a separate module, which uses a previously computed temperature history. The current flow module considers vertical flow only, as a function of radial coordinate. This computation in a separate module has the disadvantage of requiring the use of a separate program for such cases. The advantage is that flow computations, which can be time consuming, only have to be made when they are desired, which is expected only in relatively few cases. CORCON had no flow option.

Fission product migration codes are not expected to be an urgent item in these accidents as fuel temperatures remain low and few fuel failures are anticipated. BNL has reviewed earlier versions of the GA SORS codes [7]. Later versions have received a partial review during the Source Term Study [8]. A recent KFA code, FRESCO, [5] was developed and applied for pebble bed reactors. If required an evaluation of these codes can be provided later.

It should be noted that the temperature levels of the 1170 MW PCRV design are significantly higher than those of the other concepts and some of the above comments would not apply for that concept. However, its temperature levels are lower than those of the 2240 MW BASE LINE ZERO design which was analyzed in the Source Term Study [8], and we would be sufficiently well equipped to handle its transients with our current code capabilities. 
Similar to the LCS in previous PCRV reactor designs, the RCCS assumes a crucial role in safety and investment protection in modular HTGRs. Details of the RCCS designs have not become available yet.

For comprehensive evaluations of the cooling panel transients, some of our specialized codes for LCS transients [9] could most 1ikely be adapted. These cover detailed multi-dimensional thermal analyses of 1 iner and cooling tube assemblies under peak loads, as well as flow redistributions and flow reductions due to boiling in parallel tube paths. Only once more details are available can specific code applications and/or modifications be suggested.

Any RCCS systems analyses, including heat exchangers and pumps, could be handled with the general systems code MINET [11], which will be covered in Section 3.2 in more detail.

Reactor Building Atmosphere

During the relatively slow depressurized core heatup transients, any potential gas releases from components like concrete and the transfer of gases between reactor vessel, reactor cavity and environment must be analyzed. Furthermore, the $\mathrm{RB}$ gas temperature and pressure must be known.

The codes available for this purpose are the CARCAS code by GA, about which very little is known, and the ATMOS code, developed by BNL as part of the Source Term Study, and since extended to include CB temperature computations. It should be noted that these codes are not intended for $\mathrm{RB}$ models in rapid blowdown transients, but for slow core heatup transients extending over days with significant gas ingress from the core to the RB. (For RB transients during blowdown, see Section 3.4).

For current PCRV designs, the transients to be expected are milder than those of our previous evaluations and the ATMOS code could readily be applied. For confinements a minor modification would be required to change from a constant volume system to a constant pressure system (man weeks).

For modular steel vessel designs, the RB temperature is actually obtained as part of the core heatup analysis, since the heat sink is now on the outside surfaces of the RB. To modify ATMOS for such configurations is straightforward (man weeks).

For the case of simultaneous loss of RCCS in modular reactors, massive gas releases from the cavity concrete must be expected. The magnitude of the vapor releases can be evaluated with the VAPMIG code and the $\mathrm{CO}_{2}$ releases follow directly from the core heatup temperature analysis. To incorporate use of these gas sources into the ATMOS code for an overall atmosphere evolution would require some more code changes ( 1 or 2 man months). However, such scenarios do not appear to be of any urgency at this time, and work could be deferred until a later date. 
It should be noted, that in contrast to PCRV gas releases, concrete gas releases from cavity concrete would not result in the formation of combustible gases as long as vessel integrity is maintained and the $\mathrm{H}_{2} \mathrm{O}$ and $\mathrm{CO}_{2}$ cannot reach the graphite.

\subsection{NSSS Transients with Convective Heat Removal}

Most postulated HTGR transient events fall into this broad category, including all operational transients and most anticipated accidents. These include events in which there is no reactor scram, $1 . e$. , the Anticipated Transient Without Scram (ATWS). While analysis of the ATWS events is much like analysis of the other events covered in this section, ATWS is traditionally treated as a separate class of accident, and we therefore cover ATWS in a second subsection, $i . e$. , apart from transients in which scram occurs.

Events covered in this section are characterized by significant reactor heat removal via convection, i.e, fluid passing through the reactor absorbing heat and giving said heat off at some place away from the reactor. This is in contrast to a transient where the primary system integrity has been compromised and the heat removal may be dominated by conduction and/or radiation, or the ingress of water or air into the system may cause chemical reactions in the reactor. It should be noted that several of these more severe accidents could evolve from the events covered in this section, and the analysis required for Section 3.2 events may have a bearing on preventing or mitigating the more severe events.

Many transients can be included in this section. For the sake of discussion, we can break these into three broad categories:

1) Loss of the principal heat sink (LOHS) events, where a failure in the primary loop, the steam generators, or the balance of plant triggers a transient whereby the plant goes from a power producing mode to a decay heat removal mode. A break in the secondary system falls into this category, even though it is a loss-of-coolant event with respect to the steam system itself. Note that convective heat removal could be through forced circulation, i.e., the circulators driving the flow, or via natural circulation. At the lower flow rates and higher temperatures, multidimensional effects could become significant in the reactor.

2) A partial loss of coolant accident, in which an opening develops in the primary loop and some of the helium escapes. Of course, a large leak would probably result ultimately in an ingress event, but these events are discussed in another section.

3) A reactivity transient, in which the reactivity is inadvertently altered, leading to a change in power and the subsequent transient response. Again, multi-dimensional effects could become important, particularly if the power distribution is significantly changed during the transient.

The computer codes that we have considered for the analysis of events covered in this section are listed in Table 3.2-1. We have tried to make this table fairly complete, but there is a very real possibility of codes missing from the table and yet being useful. 
One obvious trend in Table $3.2-1$ is that many of these codes represent the prismatic core HTGR, as most prior emphasis in the U.S. has been on this class of HTGR cores. In those codes where a pebble bed core can be represented, this is either because the code is quite generalized and easily adaptable, or because it was developed by the Germans, who currently operate pebble-bed reactors.

In order to fill between the lines of Tables 3.2-1, a brief description is provided below for each code. Because many of these codes were developed for the analysis of systems pre-dating the current modular HTGR designs being considered, the flexibility and adaptability each code becomes a major consideration.

Table 3.2-1 Codes for Section 3.2

\begin{tabular}{|c|c|c|c|}
\hline CLASSIFICATION & CODE & DEVELOPER & APPLICABILITY \\
\hline Systems & $\begin{array}{l}\text { CHAP [10] } \\
\text { MINET [11] } \\
\text { ORTAP [12] } \\
\text { RATSAM [13] } \\
\text { TAP [14] } \\
\text { THERMIX [15] }\end{array}$ & $\begin{array}{l}\text { Los Alamos } \\
\text { Brookhaven } \\
\text { Oak Ridge } \\
\text { GA } \\
\text { GA } \\
\text { KFA }\end{array}$ & $\begin{array}{l}\text { A Few Plant Designs with Prismatic } \\
\text { Cores } \\
\text { General Thermal-Hydraulic Systems } \\
\text { Prismatic, See CORTAP, ORECA, BLAS } \\
\text { Primary Loop and Simplified Steam } \\
\text { Generator } \\
\text { Prismatic Core (with Kinetics) } \\
\text { Systems } \\
\text { Pebble-Bed Core, Plus Some Systems } \\
\text { Capabilities }\end{array}$ \\
\hline 1-D Core & CORTAP [16] & Oak Ridge & $\begin{array}{l}\text { Single Channel Prismatic, Including } \\
\text { Kinetics }\end{array}$ \\
\hline Multi-D Core & $\begin{array}{l}\text { COBRA-IIIC } \\
\text { [17] } \\
\text { NAKOGAS [18] } \\
\text { ORECA [19] } \\
\text { THERMIX Core }\end{array}$ & $\begin{array}{l}\text { Battelle } \\
\text { KFA } \\
\text { Oak Ridge } \\
\text { KFA }\end{array}$ & $\begin{array}{l}\text { Generalized, Some Pebble-Bed } \\
\text { Capability } \\
\text { Pebble-Bed Core, Fu11 Transient } \\
\text { Formulation } \\
\text { Prismatic Core } \\
\text { Pebble-Bed Core } \\
\text { Quasi-Steady-State Coolant } \\
\text { Calculations }\end{array}$ \\
\hline $\begin{array}{l}\text { Steam } \\
\text { Generator }\end{array}$ & BLAST [20] & Oak Ridge & $\begin{array}{l}\text { Steam Generator Transients, } \\
\text { Including Secondary Side Blowdown }\end{array}$ \\
\hline
\end{tabular}


CHAP [10] Developed by Los Alamos, this code is for the transient analysis of the 1) Fort St. Vrain Plant or the 2) 3000 MWt unit designed a few years back. It was also used for the analysis of the 2240 MWt design considered recently, as this design had similarities to the 3000 MWt unt already factored into CHAP. This code contains considerable detail in the modeling, and undoubtedly was quite valuable in analyzing those particular plant designs. CHAP was developed to utilize the LASAN [21] transient analysis package, which contains generalized matrix solvers for analysis in both the time and frequency domains. Although this would appear to make CHAP an easily adaptable (for other designs) code, a careful check of the programming indicates otherwise. Without a major development effort, this code is unlikely to be useful at this stage in analyzing the current modular HTGR designs. Even if an applicable version of CHAP were avallable, an extensive amount of design detail would be needed to facilitate utilization of such an extensive representation of the plant systems. Thus, this code would be more useful in a few years when more details about the plant become available.

MINET [11] Developed by Brookhaven, MINET has been widely used in the analysis of reactor systems, including LWR and LMFBR systems [22-26]. As it was developed for the simulation of a "generic" balance of plant, which are similar for all steam cycle plants, it contains several sets of fluid properties, including water/steam, helium, alr, sodium, and NaK. A fully variably dimensioned code, MINET is based on momentum integral [29] modelling, which has substantial advantages for the analysis of large systems during most transients of interest - the only limitation being very rapid transients where pressure waves must be tracked using local momentum equations. Using MINET, the user pieces together his system using models for pipes, pumps, valves, heat exchangers, turbines, tanks, etc., and specifies which fluid is passing through which parts of the system. As the system configuration is determined entirely through input data, the same MINET code library is currently used in simulating several diverse systems. While MINET lacks a few of the HTGR specific models present in some of the codes designed especially for HTGR analysis, it is easily modified, and can be interfaced with other codes for concurrent execution, thus facilitating a more complete analysis of plant systems. Two other advantages to the MINET code are its complete independence from the other HTGR design and licensing tools, and its validation base, which includes LWR AND LMFBR studies.

ORTAP [12] Developed by Oak Ridge, ORTAP is a combined form of the CORTAP [16], ORECA [19], BLAST [20], and ORTURB [27] codes. The inclusion of CORTAP and ORECA indicates the reactor representation is for the prismatic core. There are indications of some flexibility in the system configuration. The applications of this code to date have been very limited.

RATSAM [13] Developed by General Atomic, the code represents the primary loop of the system under transient conditions (no steady-state solver). While developed mostly for depressurization accidents, it could have other applications, particularly for transients that are not overly long in duration and do not require a detailed representation of the steam system. This code has been reviewed and revised at BNL [28], a simplified steam generator representation has been added, and some applications to HTGR systems have been made as part of the source term study. 
TAP [14] Also developed by General Atomic, TAP was designed for the analysis of prismatic core HTGR nuclear steam supply systems. While the code documentation indicates considerable flexibility as to what systems can be represented using TAP, the program listing appears to contradict this claim somewhat. Apparently, the TAP code has not been actively kept up-to-date.

THERMIX [15] Developed by the Germans and virtually undocumented, THERMIX is considered by some to be an industry standard. It is not only designed for pebble-bed reactors, but it has been tested against data from pebble-bed test facilities. While THERMIX 1 tself appears to represent 1 ittle more than the reactor and the primary loop, there are indications of various programs and sub-programs that can represent other portions of the system to augment the basic THERMIX calculations.

CORTAP [16] Developed by Oak Ridge, this code provides a single fuel channel representation of a prismatic core HTGR reactor, and includes point kinetics. It does not appear to hold great potential for the analysis of a pebble-bed reactor.

COBRA IIIc [17] Developed by Batelle Northwest Laboratories, COBRA is a code with an extensive history in the simulation of other reactor core types. Because of its flexibility, COBRA has to be considered at this time, although its usefulness in HTGR analysis is far from certain. It has been modified and applied to pebble-bed cores, with some success, although the authors stated some reservations about the cross flow calculations [17]. As its underlying models are based on momentum integral [29], the same as the the MINET code, it is quite possible COBRA will function well for several fluid types, as MINET does.

NAKOGAS [18] Developed by the Germans, this pebble-bed core transient analysis code contains a complete transient two-dimensional flow field solution, making it more detailed (and probably considerably slower) than THERMIX. Also included is some cursory modeling of the primary loop. NAKOGAS has been applied in several German studies of pebble-beds. There are indications that, due to the slow computational speed and other numerical problems with NAKOGAS, the THERMIX code may be more useful and useable.

ORECA [19] Developed by Oak Ridge, this code was developed to simulate the prismatic cores in 1) Fort St. Vrain, 2) the 2000 MWt Summit Station, and 3) the 3000 MWt Fulton Station. The code was also used to simulate the 2240 MW HTGR and has been modified to represent other designs, as well. A multichannel flow representation and a 3 -dimensional conduction representation is provided.

THERMIX CORE [15] As this code is alternately referred to as a core code and a systems code, it appears twice in Table 3.2-1. It can handle multi-dimensional convection in pebble-bed cores, using two-dimensional, quasi-steady mass and energy conservation equations and a momentum equation that neglects the Inertia term.

BLAST [20] Developed by Oak Ridge, this code is for the transient analysis of steam generators. Equations conserving mass, energy, and momentum are 
integrated over time, on a local basis, to determine the transient temperatures, pressures, and flow rates on the secondary side. Conservation of energy equations are used to determine the helium (primary side) and tube temperatures.

\subsubsection{Transients with Scram}

If a scram occurs, the core reactivity can be assumed to fall off very quickly, and the core power level can be predicted using pre-determined decay heat curves. This means that one really doesn't need neutron kinetics or reactivity feedback mechanisms, except for the reactivity transients. Thus, the codes lacking neutron kinetics models are not excluded from the analysis of many of these transients.

The potential for utilizing each of the codes for analyzing the three broad transient categories is indicated in Table 3.2-2. As with Table 3.2-1, it is quite possible that one or more viable candidates for the analysis has been left out.

Al1 of the codes under consideration have at least some potential for the analysis of the loss of heat sink events. For prismatic core systems, CHAP would be a good choice for a system that it is capable of representing, RATSAM would work well for short transients having minimal dependence on balance of plant response, TAP and ORTAP could perform well if the correct system layout could be obtained, and MINET, valuable because of its great flexibility, would be even more so with a prismatic core option or interfaced with a prismatic core code. For the analysis of pebble-bed systems, THERMIX provides a good representation of the reactor with some systems representation, and MINET can represent the system in whatever detail that is required, and uses a simpler core representation. For representing the prismatic core, CORTAP can provide a reasonably good representation if a single fuel channel is acceptable and multi-dimensional effects are negligible, and ORECA can represent the multidimensional conduction, once the reactor has been shut down. If THERMIX and/ or NAKOGAS are avallable, a reasonably good representation of the pebble-bed core should be at hand, and COBRA IIIc will still be in reserve as a possible option. In representing the steam generators, BLAST could be useful, especially for rapid transients on the secondary side, and MINET can be used for any non-blowdown transients.

For representing the loss of primary coolant events, the choice of codes is not nearly as broad. The CHAP, CORTAP, MINET, ORECA, TAP, THERMIX, and COBRA codes all treat pressure on a non-local basis, so their application must be limited to events where the change in pressure is not extremely rapid, as pressure waves cannot be tracked in the system. The remaining codes, $1 . e$. , the ones that can track a rapid pressure transient are RATSAM, NAKOGAS (probably), and BLAST (secondary side only). While this appears to be a problem, one should realize that many of the transients will be slow enough to be considered "gradual", and that, thus, many of the key codes are still applicable.

In order to represent the reactivity transients, reactor kinetics must be part of the modeling, and a good deal of system representation must be included. Thus, our options for the prismatic core systems become CHAP, ORTAP, and TAP, and MINET (if a prismatic core representation is added). For the pebble-bed system, the choices remain THERMIX and MINET. 
Table 3.2-2 Analyzing Section 3.2 Events

\begin{tabular}{|c|c|c|c|c|}
\hline CLASSIF ICATION & CODE & LOSS OF HEAT SINK & $\begin{array}{c}\text { LOSS OF } \\
\text { PRIMARY COOLANT }\end{array}$ & $\begin{array}{l}\text { REACT IVITY } \\
\text { TRANS IENTS }\end{array}$ \\
\hline Systems & $\begin{array}{l}\text { CHAP [10] } \\
\text { MINET [11] } \\
\text { ORTAP [12] } \\
\text { RATSAM [13] } \\
\text { TAP [14] } \\
\text { THERMIX [15] }\end{array}$ & $\begin{array}{l}\text { Some Prismatic } \\
\text { Reactor Systems } \\
\text { Yes } \\
\text { Prismatic Cores, } \\
\text { Options Limited } \\
\text { Primary Loop On1y } \\
\text { Yes, for Prisma- } \\
\text { tic Core Systems } \\
\text { Pebble-Bed }\end{array}$ & $\begin{array}{l}\text { Except rapid } \\
\text { blowdown } \\
\text { Except rapid } \\
\text { blowdown } \\
\text { Except rapid } \\
\text { blowdown } \\
\qquad \text { Yes } \\
\text { Except rapid } \\
\text { blowdown } \\
\text { Except rapid } \\
\text { blowdown }\end{array}$ & 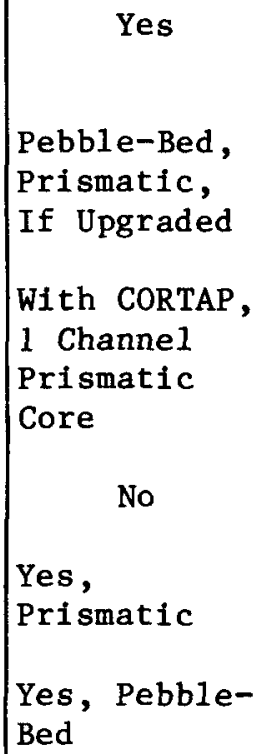 \\
\hline 1-D Core & CORTAP [16] & Prismatic Core & $\begin{array}{l}\text { Except rapid } \\
\text { blowdown }\end{array}$ & $\begin{array}{l}1 \text { Channel } \\
\text { Limited } \\
\text { Options }\end{array}$ \\
\hline Mu1ti-D Core & $\begin{array}{l}\text { COBRA-IIIC } \\
{[17]} \\
\text { NAKOGAS [18] } \\
\text { ORECA [19] } \\
\text { THERMIX Core }\end{array}$ & $\begin{array}{l}\text { Yes } \\
\text { Pebble-Bed } \\
\text { Prismatic Core } \\
\text { Pebble-Bed }\end{array}$ & $\begin{array}{l}\text { Except rapid } \\
\text { blowd own } \\
\text { Yes } \\
\text { Except rapid } \\
\text { blowdown } \\
\text { Except rapid } \\
\text { blowdown }\end{array}$ & $\begin{array}{c}\text { No } \\
\text { No } \\
\text { No } \\
\text { Yes, Pebble }\end{array}$ \\
\hline $\begin{array}{l}\text { Steam } \\
\text { Generator }\end{array}$ & BLAST [20] & $\begin{array}{l}\text { In Steam Genera- } \\
\text { tor, Particularly } \\
\text { Secondary Blowdown }\end{array}$ & $\begin{array}{l}\text { Steam Generator } \\
\text { Response on } 1 \mathrm{y}\end{array}$ & Not Useful \\
\hline
\end{tabular}

In order to assure the necessary computer code library to handle the three types of transients considered in this subsection, i.e., loss of heat sink, loss of coolant, and reactivity, we recommend the following actions:

For representing the loss of principal heat sink events, many tools are available, if one assumes the avallability of THERMIX and NAKOGAS. Should all 
of the codes listed be available, the main concern will be flexibility, particularly with the proposed design continually evolving. We know the MINET code to be highly flexible, and know that several of the other codes are very 1nflexible, but in some cases could use help from the original code developers as to how flexible some of these codes are. Should the German codes be unavallable, a pebble-bed core representation will have to be acquired somehow, through either COBRA, MINET, or a new code.

The situation in representing the loss of primary coolant transients is much the same, as long as the transient is not extremely rapid. The limited need for analyzing the rapid events, which requires treatment of coolant pressure on a local basis, may not justify a major upgrading of our code capabilities at this time.

For representing the reactivity transients, the prismatic systems tools may require an increase in flexibility, but appear to offer a reasonably good starting point. Further, incorporation of a simple prismatic core representation in MINET would provide the needed flexibility for analyzing those transients not requiring a detailed core model. The THERMIX and MINET codes offer strong possibilities for the pebble-bed reactivity transients, particularly if they can be interfaced to take advantage of the strengths of each code. It should be noted that the determination of reactivity feedback coefficients requires the use of neutronics codes, which are to be covered in Section 3.5 .

\subsubsection{Transients Without Scram (ATWS)}

When there is no reactor scram, or a delayed one, it becomes necessary to determine the rate of heat production in the core. Thus, neutron kinetics and the various reactivity feedback mechanisms have to be factored into the analysis. Other than this consideration, the analysis will be very similar to that covered in Section 3.2.1, particularly the parts concerning reactivity transients.

For the prismatic core system, the CHAP, ORTAP, and TAP codes are solid possibilities, and MINET could be used if a simple prismatic core representation were added to the code (a modest code enhancement). CHAP has already been used for ATWS analysis, so the major question there is whether it can handle the various systems under consideration. The ORTAP or TAP codes could be used, should they be flexible enough to cover the systems under consideration. Implementation of a prismatic core option into MINET should be quite straightforward, should the options to use CHAP, ORTAP, or TAP for prismatic core systems prove overly difficult.

Two codes, THERMIX and MINET, are clear choices for analyzing ATWS events in pebble-bed systems. The multi-dimensional core representation in THERMIX could be useful, particularly for low flow transients. MINET provides the flexibility to represent any of the system layouts under consideration.

As the MINET code was not applied to HTGR systems analysis before January, 1985, and as we wanted to determine its potential for analyzing HTGR ATWS events, we added a simple pebble-bed core representation and ran four ten minute transients. The core model included two pebble types per axial node, one

for the fuel pebbles and one for the moderator pebbles. Temperatures within 
the pebbles were assumed to be uniform at the surface temperature. Point kinetics were used to determine the reactor power, and the reactivity feedback due to changes in the fuel and moderator temperatures was accounted for separately, using the temperature coefficient curves in Figure D-2 of Reference 8 . Heat transfer and pressure drop correlations for the pebble-bed [30] were factored into the calculations. Each ten minute transient required about one minute of $\operatorname{CDC} 7600$ computer time, although the calculations can be made faster if we allow the much larger time steps that current MINET calculations indicate are possible (it prints out minimum time constants in the twenty to fifty second range for the system being analyzed).

The MINET representation utilized in simulating the VIL modular HTGR system documented in Reference 2 is shown in Figure 3.2.1. The representation includes the core (a modified heated pipe), the steam generator, the circulator (pump), the plena and piping, and a small portion of the steam system. As MINET needs reference values to perform the steady-state calculations, lines to and from the helium purification system are included, although the flow rate through these lines is so tiny as to be inconsequential. With the exception of the code modifications to represent core, this representation was created entirely through input data and uses the same version of MINET as is used for LWR and LMFBR systems.

Four test transients were analyzed, all beginning with a loss of feedwater (ramped to 0.0 flow in 10 seconds) and a failure to scram. Additional assumptions were made for each of the four cases:

Case 1) No circulator trip and no auxiliary feedwater

Case 2) Circulator trip at 5 seconds, no auxiliary feedwater

Case 3) No circulator trip, auxiliary feedwater at 30 seconds

Case 4) Circ trip at 5 seconds, aux feedwater at 30 seconds.

Results for these runs are shown in Figures 3.2.2 through 3.2.17.

Results for Case 1 are shown in Figures 3.2.2 through 3.2.5. The feedwater flow rate ramps down to zero during the first ten seconds to initiate the event, and the primary flow rate remains approximately constant, as the circulator fails to trip. With the reactor remaining at power and the primary flow continuing, the water inventory in the steam generator is exhausted within 6 minutes (depending on initial water inventory, which we estimated). As the cooling capacity of the steam generator decreases, the helium outlet temperature steadily increases, and actually exceeds the inlet temperature after 7 minutes (Fig. 3.2.3), as hot residual steam transfers heat back to the now cooler helium. The reactor power decreases in response to the higher core inlet temperatures which result from reduced heat removal through the steam generator, as shown in Fig. 3.2.4. Again, the transfer of heat back through the steam generator after 7 minutes can be seen. Finally, the core average temperatures for the fuel and moderator pebbles gradually increase, particularly after the steam generator inventory is exhausted, as shown in Fig. 3.2.5. For the transient as a whole, the response of most of the system appears acceptable for a rather severe set of assumptions. However, once the steam generator inventory is exhausted, the helium temperatures in the circulator become rather high. We know the Germans are concerned about exposing their circulators to high temperatures, perhaps due to thermal stress problems, and infer that the increased helium temperatures leaving the steam generator after the 5-6 minute point in the transient are probably undesirable. 


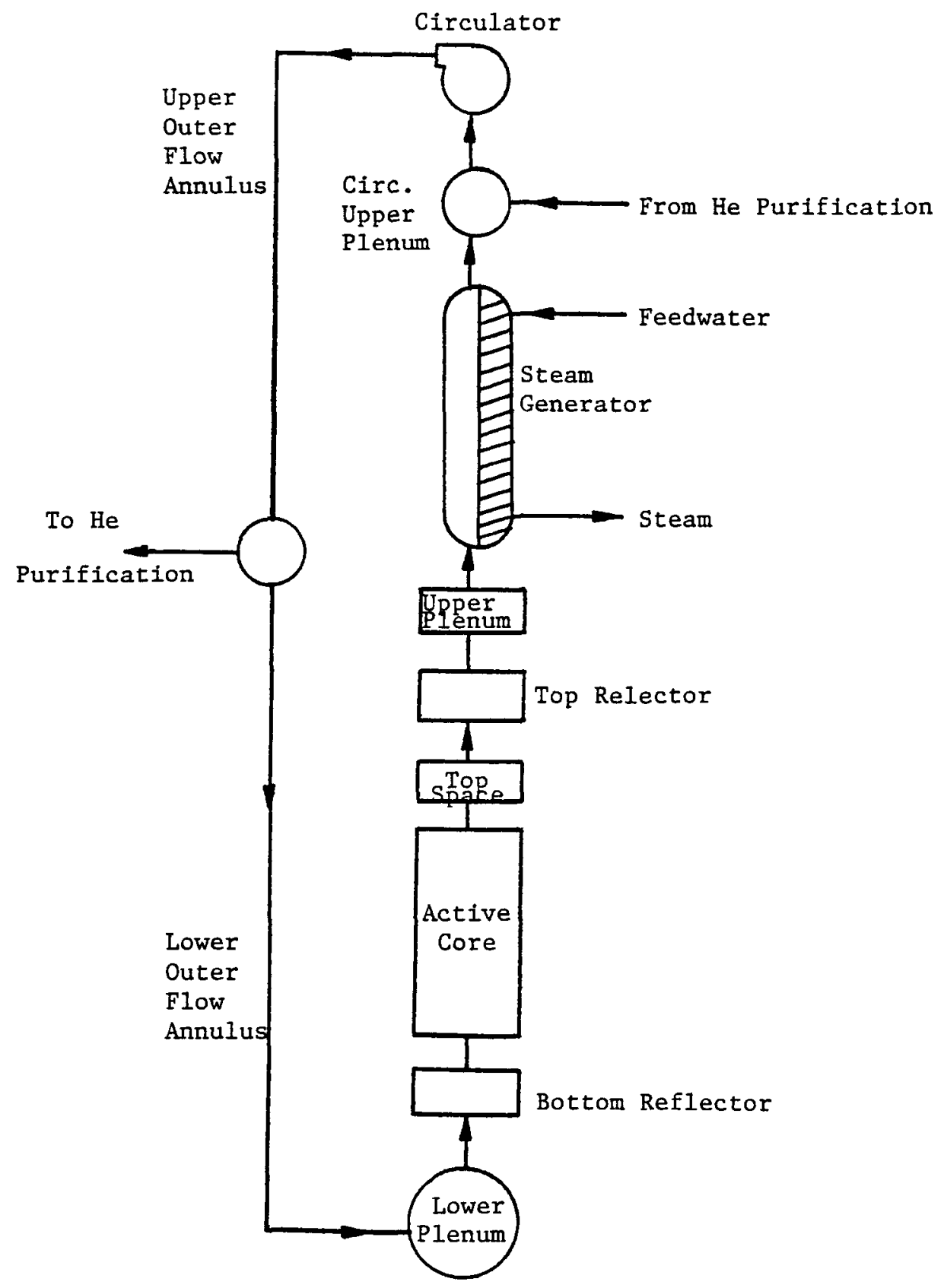

Figure 3.2.1 Representation of VIL Modular HTGR System Used in Section 3.2 ATWS Analysis 


\section{HTGR-002 LOFW ATWS \\ No Circ Trip.No AFW}

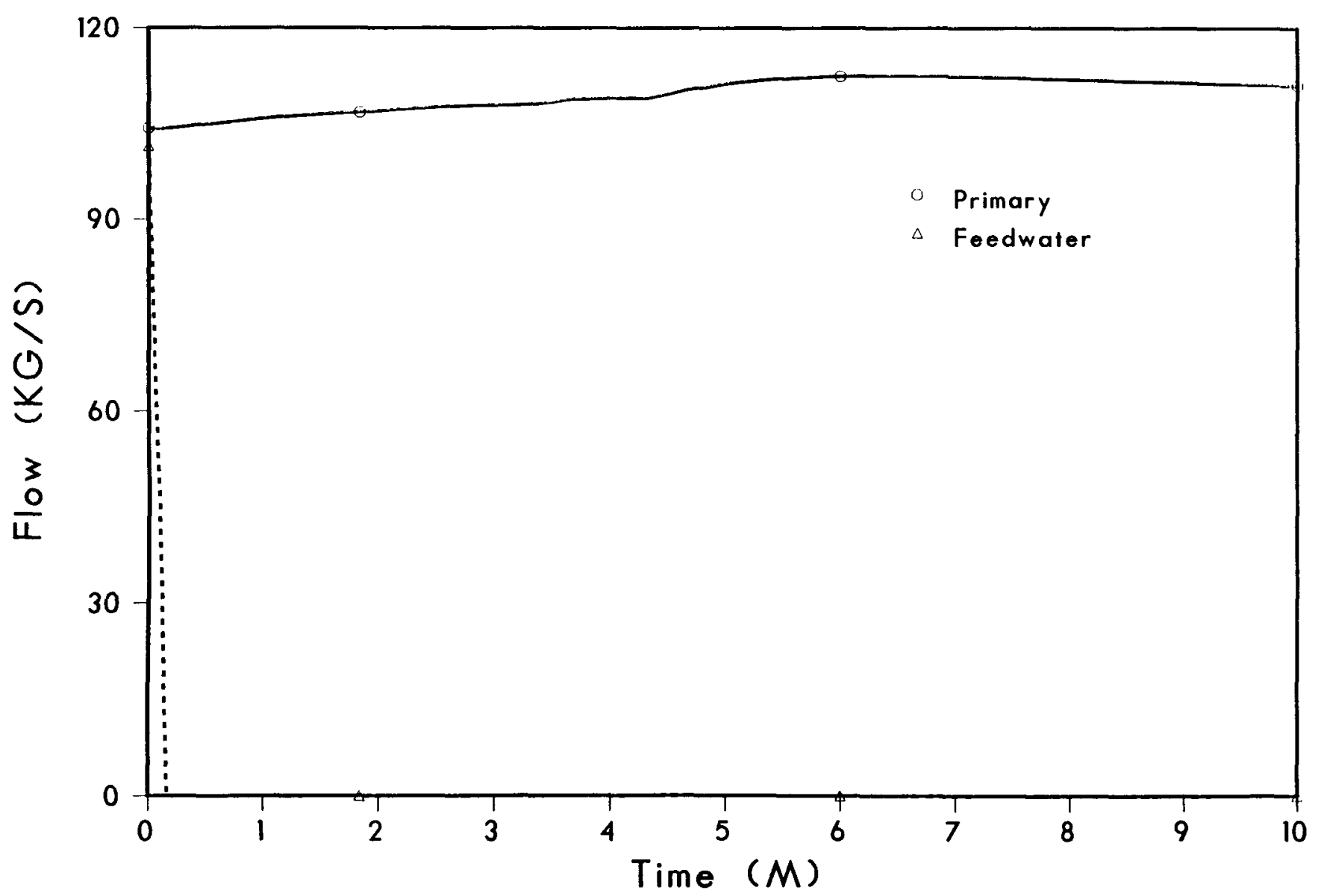

Figure 3.2.2 Case 1 Primary Loop (Hellum) Mass Flow Rate and Feedwater Mass Flow Rate 


\section{HTGR-002 LOFW ATWS \\ No Circ Trip.No AFW}

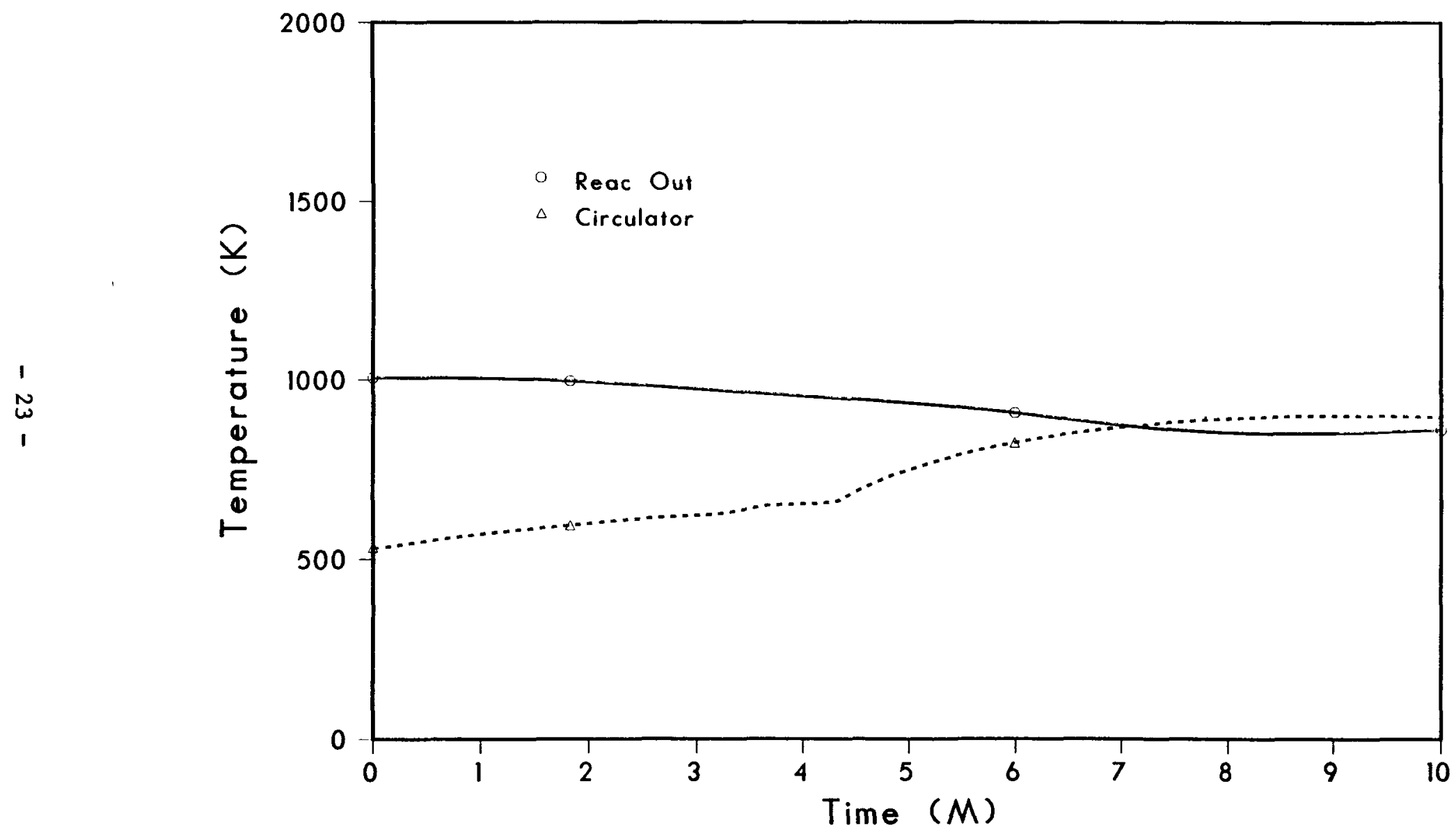

Figure 3.2.3 Case 1 Hellum Temperatures at the Reactor Outlet and the Circulator Inlet (Steam Generator Outlet) 


\section{HTGR-002 LOFW ATWS}

\section{No Circ Trip.No AFW}

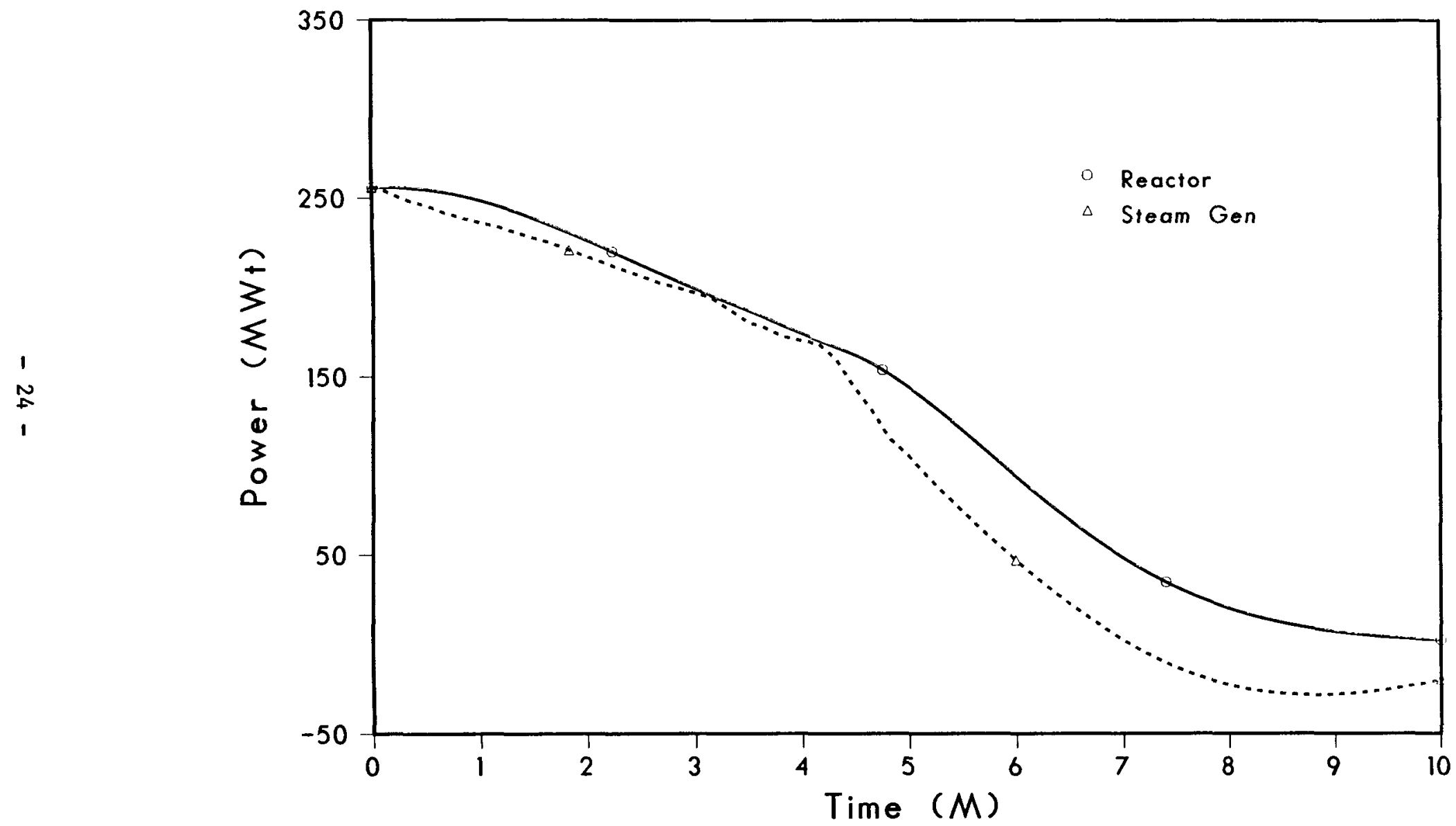

Figure 3.2.4 Case 1 Power Generated in the Core (Fuel Pebbles) and Power Transferred from Helium in Steam Generator 


\section{HTGR-002 LOFW ATWS \\ No Circ Trip.No AFW}

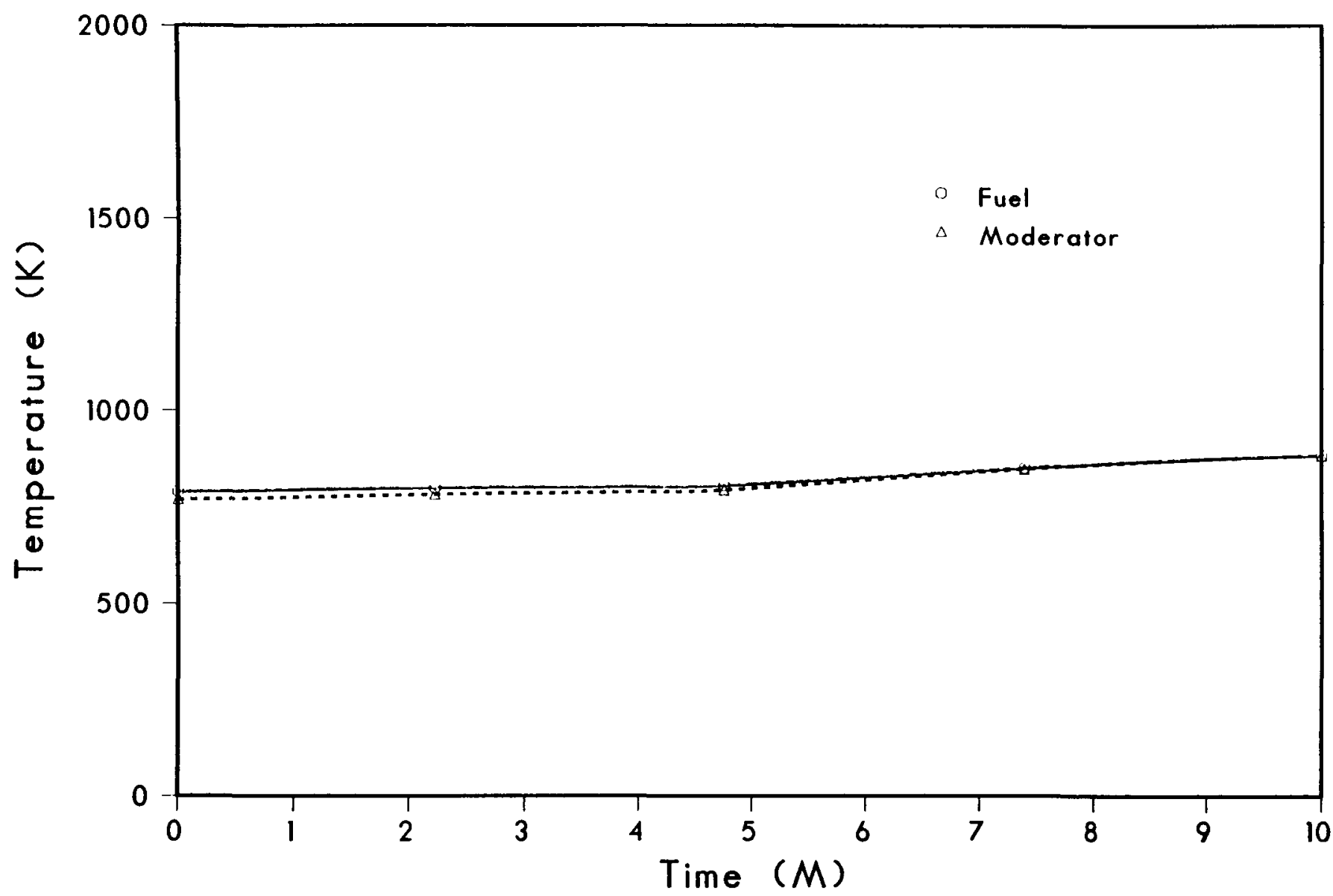

Figure 3.2.5 Case 1 Core Average Temperatures for the Fuel and Modulator Pebbles 


$$
\begin{aligned}
& =1 \\
&
\end{aligned}
$$




\section{HTGR-002 LOFW ATWS}

\section{Circ Trip at 5s.No AFW}

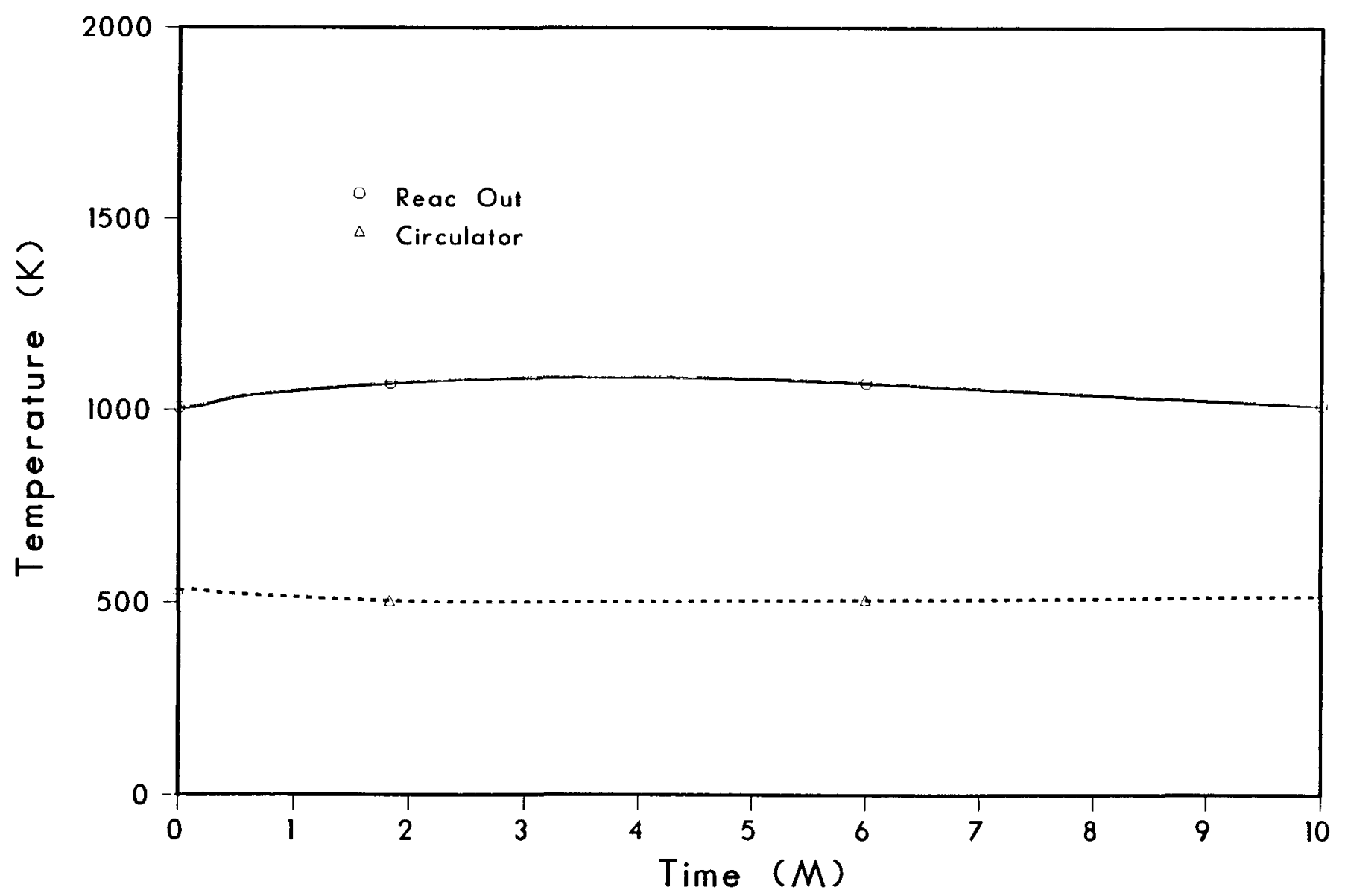

Figure 3.2.7 Case 2 Helium Temperatures at the Reactor Outlet and the Circulator Inlet (Steam Generator Outlet) 


\section{HTGR-002 LOFW ATWS}

Circ Trip at 5s.No AFW

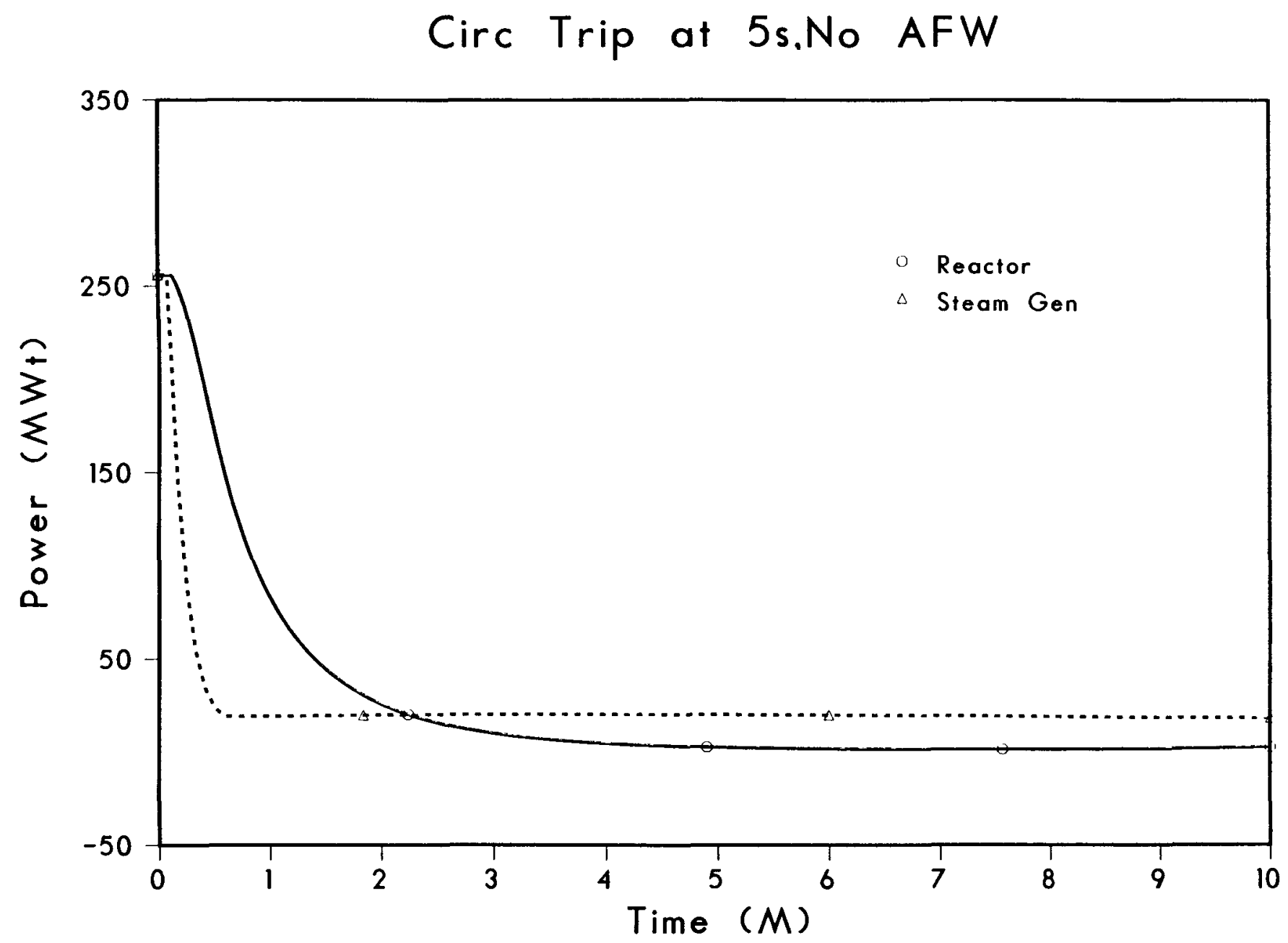

Figure 3.2.8 Case 2 Power Generated in the Core (Fuel Pebbles) and Power Transferred from Helium in Steam Generator 


\section{HTGR-002 LOFW ATWS}

Circ Trip at 5s.No AFW

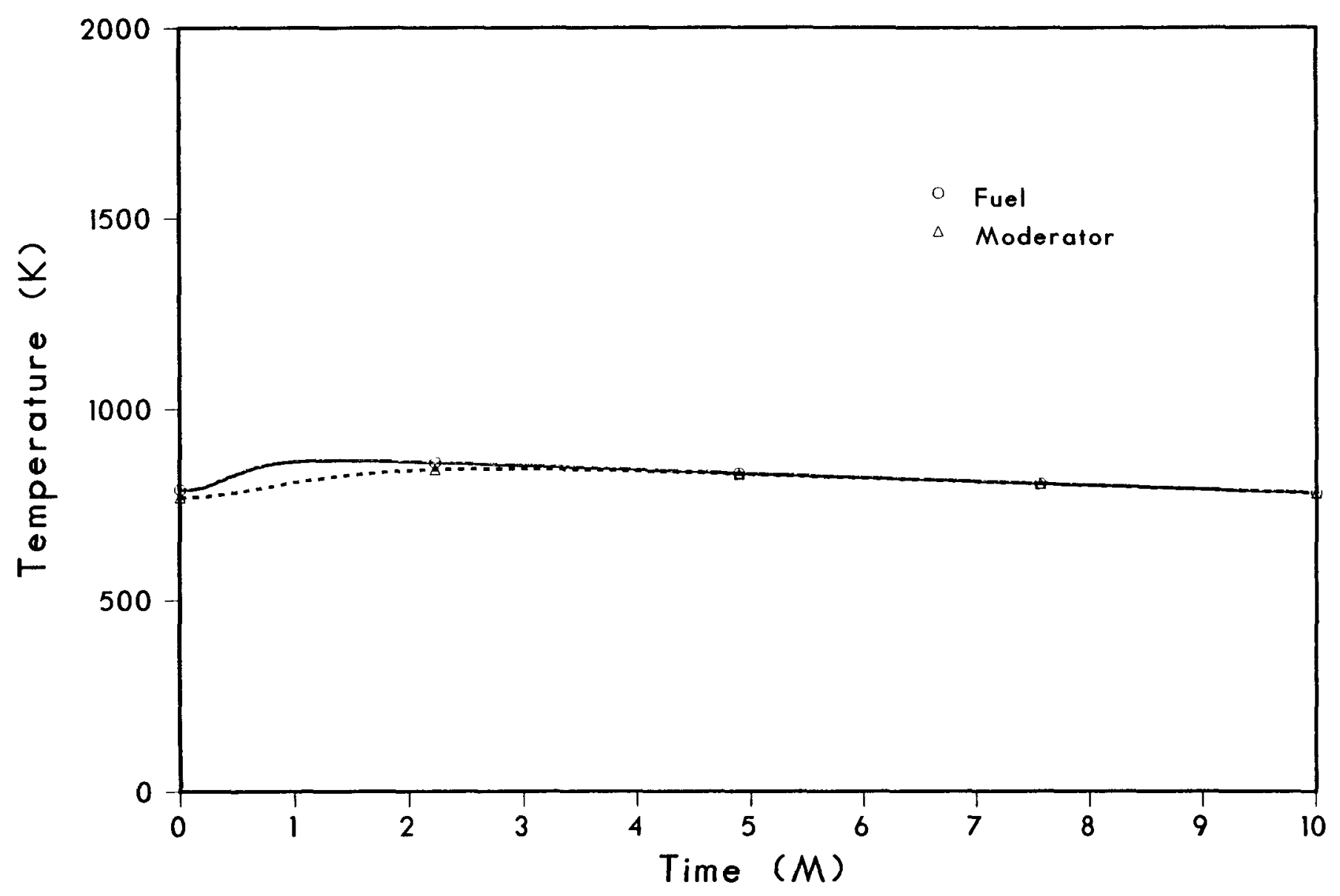

Figure 3.2.9 Case 2 Core Average Temperatures for the Fuel and Modulator Pebbles 


\section{HTGR-002 LOFW ATWS \\ No Circ Trip.AFW at 30 s}

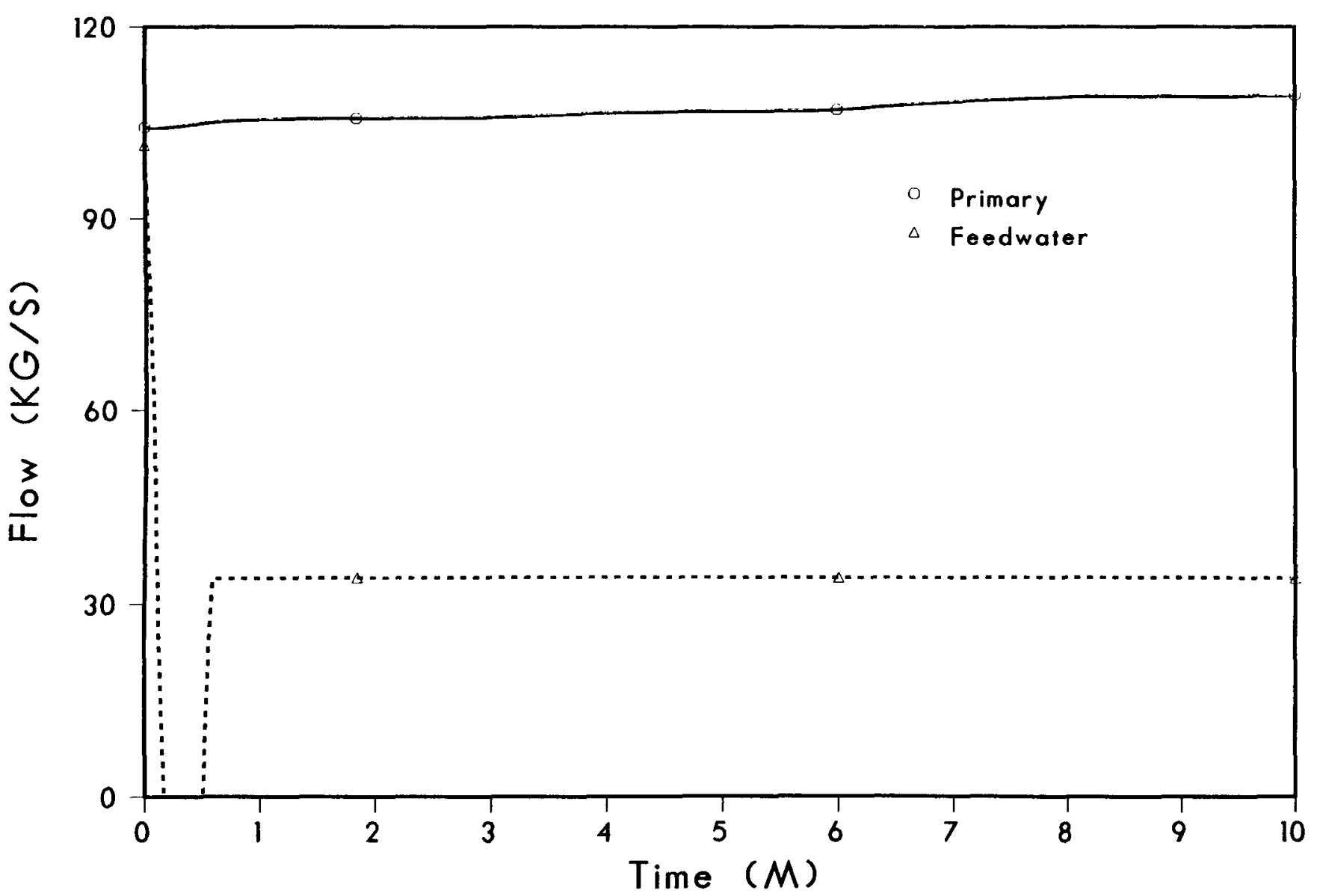

Figure 3.2.10 Case 3 Primary Loop (Helium) Mass Flow Rate and Feedwater Mass Flow Rate 


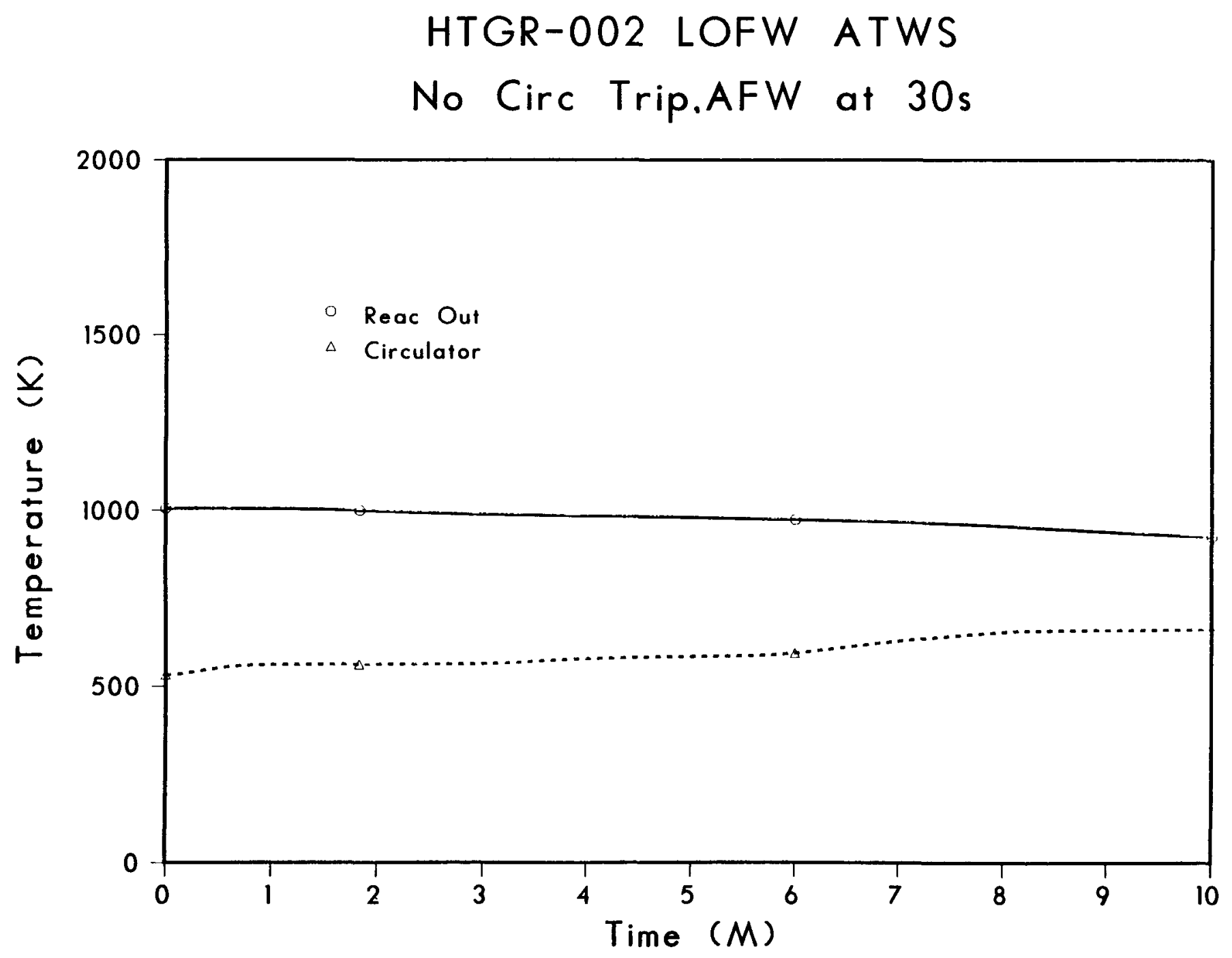

Figure 3.2.11 Case 3 Helium Temperatures at the Reactor Outlet and the Circulator Inlet (Steam Generator Outlet) 


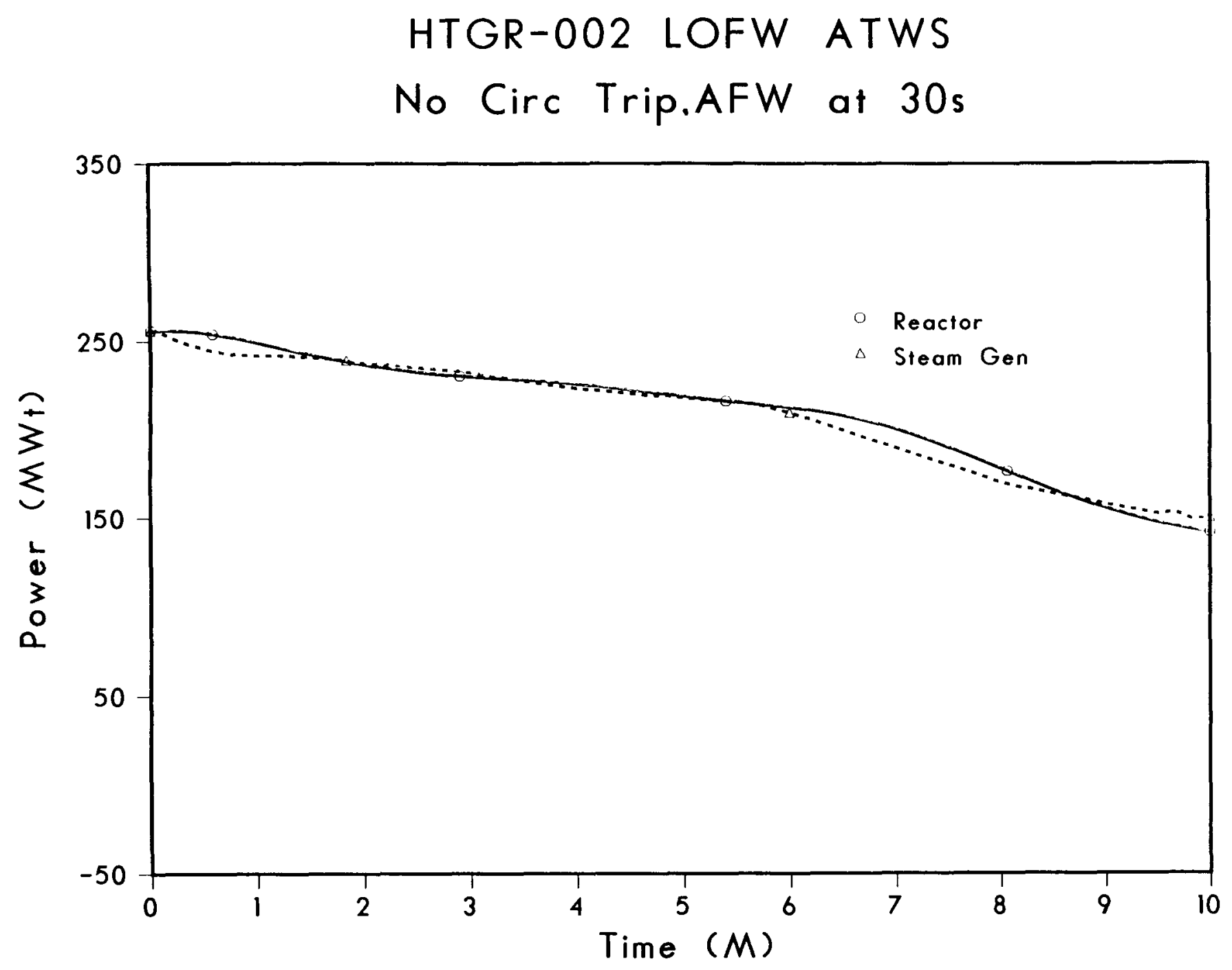

Figure 3.2.12 Case 3 Power Generated in the Core (Fuel Pebbles) and Power Transferred from Helium in Steam Generator 


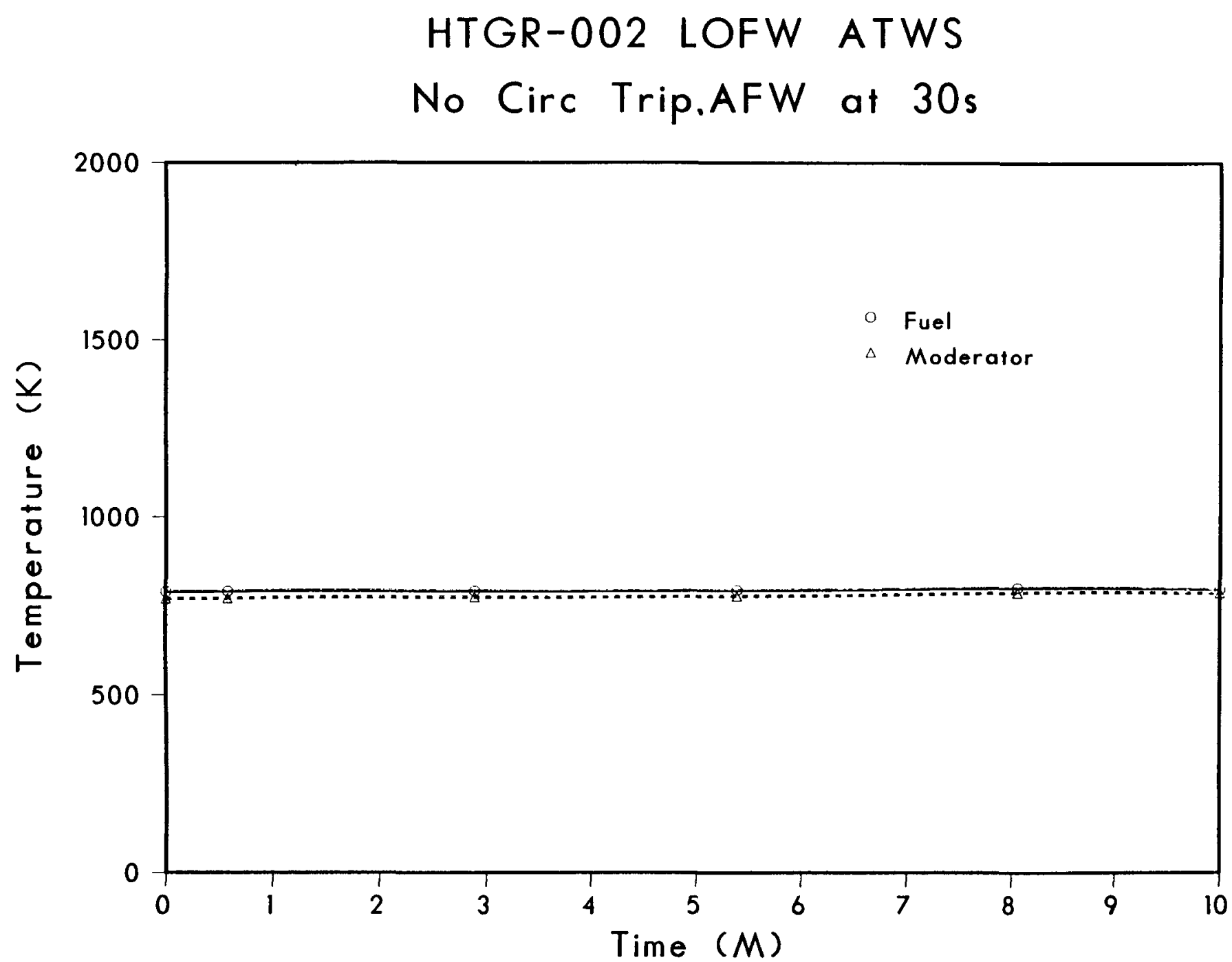

Figure 3.2.13 Case 3 Core Average Temperatures for the Fuel and Modulator Pebbles 


\section{HTGR-002 LOFW ATWS}

\section{Circ Trip at 5 s. AFW at 30 s}

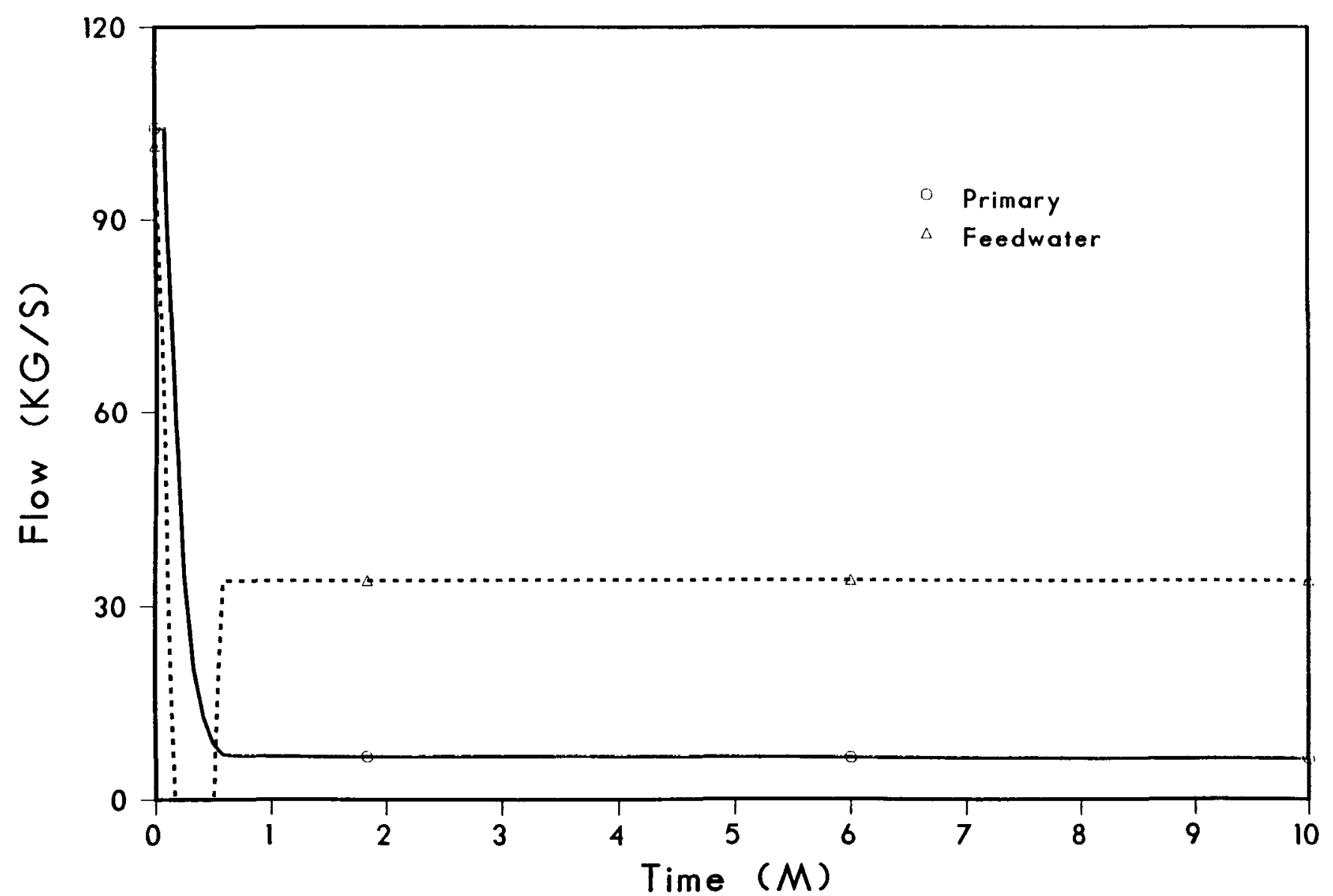

Figure 3.2.14 Case 4 Primary Loop (Helium) Mass Flow Rate and Feedwater Mass Flow Rate 


\section{HTGR-002 LOFW ATWS \\ Circ Trip at 5s.AFW at 30s}

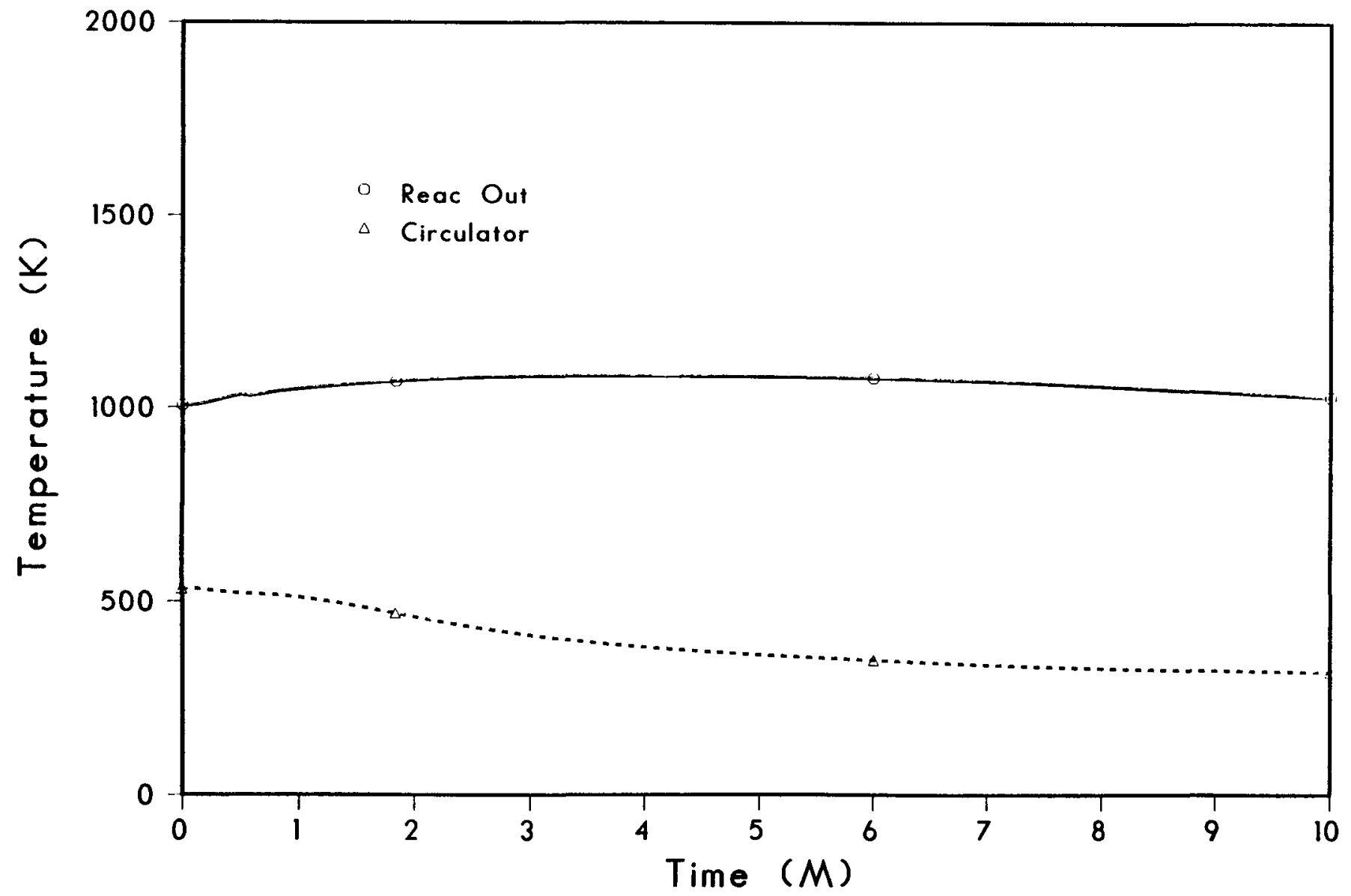

Figure 3.2.15 Case 4 Helium Temperatures at the Reactor Outlet and the Circulator Inlet (Steam Generator Outlet) 


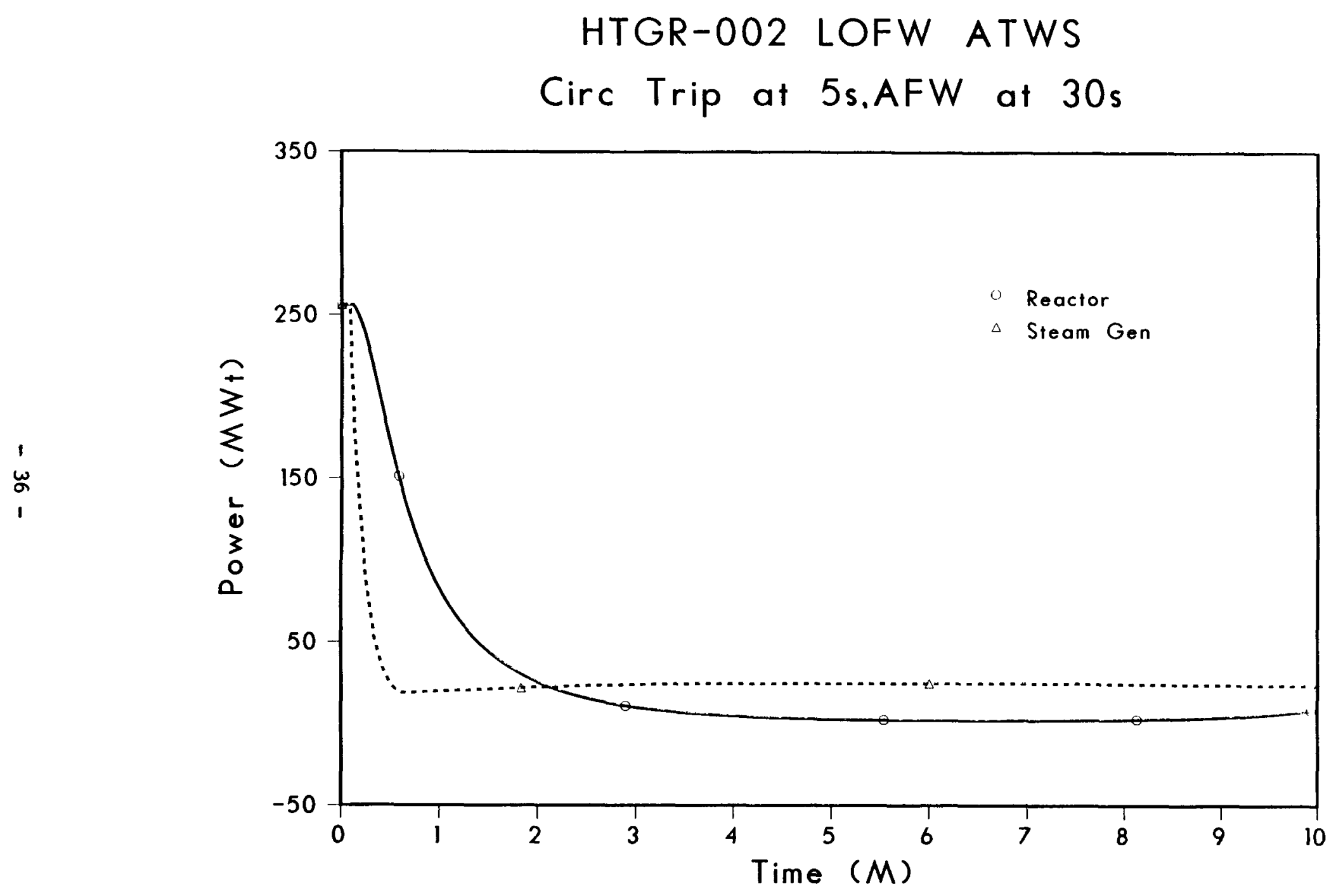

Figure 3.2.16 Case 4 Power Generated in the Core (Fuel Pebbles) and Power Transferred from Helium in Steam Generator 


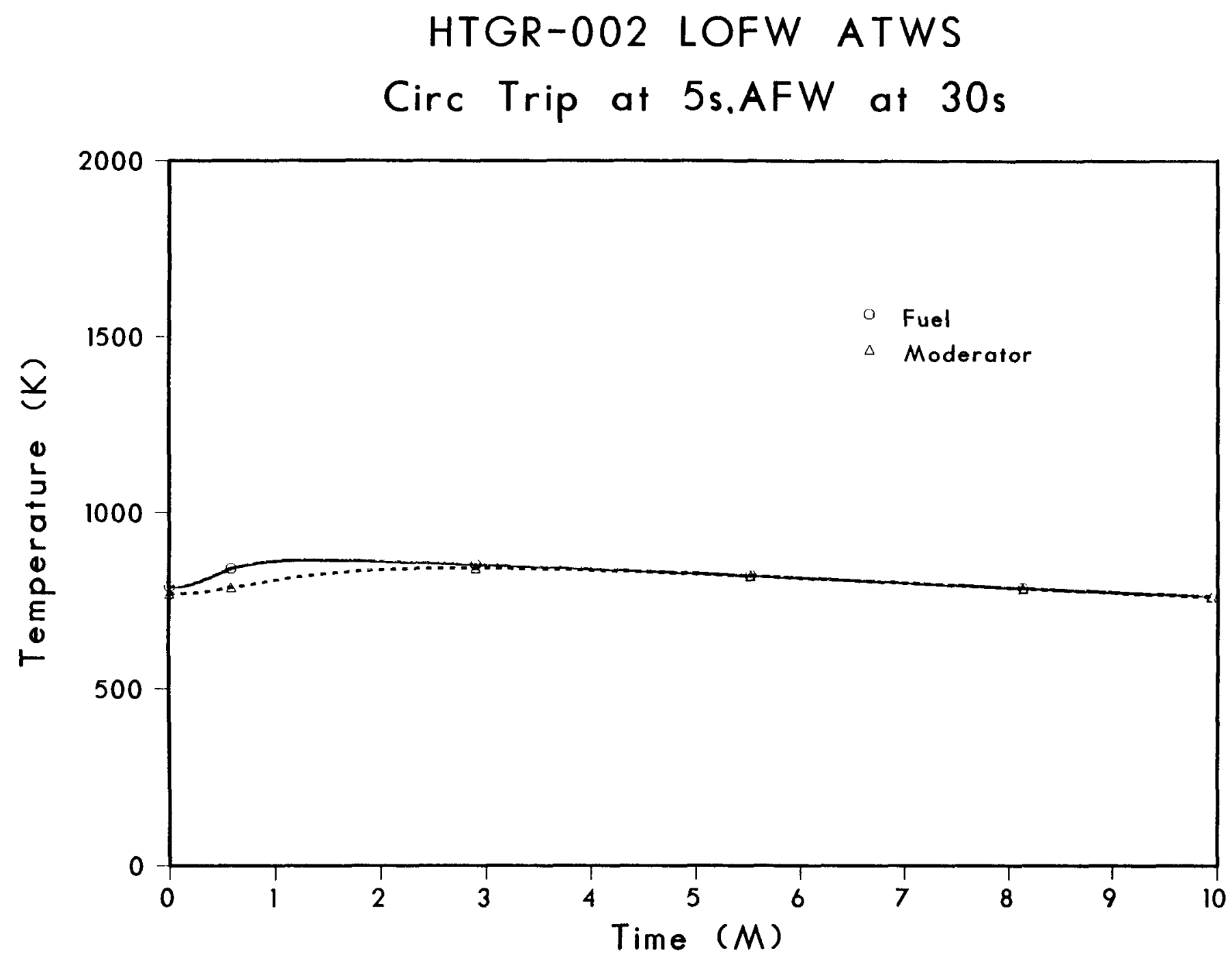

Figure 3.2.17 Case 4 Core Average Temperatures for the Fuel and Modulator Pebbles 
In Figures 3.2.6 through 3.2.9, results for Case 2 are provided. Because the circulator is tripped in this case, the primary loop flow rate drops off quickly to natural circulation flow rates. The rate of coastdown is an uncertainty, depending on the time constant for the circulator, which was estimated as 10 seconds. With the reduced flow rate, the helium resides longer in the core, and exits a little hotter. At reduced helium flow rates, the steam generator has enough cooling capacity to reduce the helium outlet temperatures to very near the water inlet temperature, at least while there is sufficient water in the undt. As shown in Figure 3.2.8, the power production in the reactor falls off in response to the hotter helium, and the heat removal rate through the steam generator is quite steady after the first minute of the transient. During the inftial 2 minutes, the fuel and moderator temperatures increase somewhat in response to the hotter helium, and then decrease as the power level drops off, as shown in Figure 3.2.9. Judging from these results, this transient could be rather benign, as long as the steam generator water inventory holds out (that appears to be over $1 / 2$ hour, judging at this stage in the analysis process).

In the third case, cold $\left(20^{\circ} \mathrm{C}\right)$ auxiliary feedwater is added after $30 \mathrm{sec}-$ onds, and the circulator is not tripped. Key results are shown in Figures 3.2.10 through 3.2.13. For this case, the plant will move toward a new equilibrium condition, as determined by the reduced heat removal capacity through the steam generator, consistent with the reduced feedwater flow rate at lower temperatures. The reduced steam generator heat removal capacity is reflected in increased helium outlet temperatures (Figure 3.2.11) and reduced core power level (Figure 3.2.12). The core average fuel and moderator pebble temperatures, shown in Figure 3.2.13, barely change at all in this transient, at least during the first 10 minutes. From these results, the system response during this sequence seems quite acceptable, although the analysis probably should continue until the new equilibrium condition is firmly established.

Results from Case 4 are shown in Figures 3.2.14 through 3.2.17. With the circulator tripped at 5 seconds and cold auxiliary feedwater provided at 30 seconds, this is probably the most 1 ikely sequence to actually occur. In Figure 3.2.15, we can see the core outlet helium temperatures increasing in response to the reduced helium flow rate, and the steam generator helium outlet temperature decreasing to the feedwater temperature, which falls off considerably as the auxiliary feedwater enters. The core power level is reduced, largely due to the longer residence time of the helium (in the core). Again, the fuel and moderator pebbles (Figure 3.2.17) heat up a little during the first 2 minutes, and fall off thereafter. In this case, a new equilibrium will ultimately be established at a low natural circulation helium flow rate, with the steam generator helium outlet temperature at the auxiliary feedwater temperature, and the core power limited by the temperature of the helium in the core.

Because this analysis is for an approximated system using new models (the pebble-bed representation in MINET), one should not place too much emphasis on the quantitative results. This work does, however, establish MINET as a viable option for HTGR ATWS analysis, and it points out some of the important factors in the analysis, particularly the need to accurately represent the steam generator, and ultimately parts of the balance of plant in the analysis. 


\subsection{Ingress Accidents}

The major ingress accident scenarios are water and/or air ingress into the primary loop, leading to graphite oxidation, possible reactivity transients and gas releases via the RB or via secondary side pathways.

Water ingress is generally due to STG component fallures (tube break, tube sheet failures, etc.), with the STG design generally limiting the maximum ingress rates. Circulator bearing cooling water can be another source of water ingress.

The major concerns from water ingress are the resulting graphite oxidation, fuel hydrolysis, fission product releases and the formation of combustible gases. The decay heat removal system must provide for rapid cooldown of the core graphite and fuel matrix to minimize the chemical reactions. As the graphite/water reactions are endothermic, there is no contribution to the core heatup process. Also, of safety significance are potential reactivity exertions due to water ingress in under-moderated cores.

Alr ingress accidents are only possible after primary loop depressurization. As the potential graphite/air reactions are exothermic, the process can add to FP decay heat, thus increasing the thermal load of the after heat removal systems. As massive air ingress would require multiple vessel failures and is counteracted even then by a significant core pressure drop requirement for prismatic as well as for pebble bed fuel, so called "graphite fires" have been considered incredible in PCRV designs. While multiple vessel failures are possibly more likely in steel vessel designs, the core pressure drop requirement remains very high, and the total available air inventory of the $R B$ is small.

Major concerns for air ingress accidents are whether a locally concentrated oxidation front can cause local fuel damage due to excessive fuel temperatures or due to burn-off of outer graphite as well as of fuel particle coatings. Furthermore, the combustible gas generated ( $\mathrm{CO}$ ) can potentially lead to dangerous burning conditions in the $\mathrm{RB}$.

\subsubsection{Typical Water Ingress Scenarios}

The normal PPS action subsequent to water ingress is scram due to high moisture content, isolation and dump of the defective main loop and cooldown via either one of the other main loops or via CACS. This accident results in minimal water ingress and prompt core cooldown without any significant consequences.

Additional accident scenarios typically considered are the following $[31,32]$ :

- Failure of the moisture monitor in the faulty STG, resulting in scram on high moisture of intact STG-1oop with dump of intact STG.

- Failure of dump valve(s) or fallure of loop secondary side isolation valves.

- Failure of all moisture monitors, resulting in scram on high primary loop pressure. 
In particular with failure to close the feedwater supply valves, failure of the secondary side relief valves can occur with subsequent discharge of primary coolant through the secondary side pathways (see Section 3.3.7).

\subsubsection{Typical Air Ingress Scenarios}

Air ingress into the primary loop requires prior depressurization with significant subsequent air inflow. Scenarios that have been considered are, for instance, a primary vessel leak such that during decay heat removal via a main loop or an auxiliary loop, significant amounts of gas can be exchanged between the primary loop and the RB, while the operating loop forces the resulting gas mixture through the core [34]. (It may be hard to conceive significant air ingress and combustible gas discharge from a single break; butonly with such a large break or with several separate breaks and with simultaneous forced flow conditions can significant amounts of air be forced through the core.) Order of magnitude computations indicate that natural circulation can only result in about .1 to $.3 \mathrm{~kg} / \mathrm{s}$ of gas circulation through the core of a typical modular pebble bed reactor. The initial $\mathrm{RB}$ air inventory of about 80 $\mathrm{kg}$ mol (even if none were lost during the initial blowdown) can only cause the burning of about $400 \mathrm{~kg}$ of graphite. Thus, a1r ingress consequences under natural circulation conditions appear to be less severe than those under the above forced cooldown scenarios.

\subsubsection{Modelling Needs for Accidents with Significant Graphite Oxidation}

The above scenarios identify the major modelling needs for the assessment of ingress accidents in which graphite oxidation is important. Reactivity transients and primary coolant escape via secondary side pathways are transients in which the oxidation plays a secondary role. These are treated in Sections 3.3 .6 and 3.3.7.

To analyze the primary loop transients prior to and during ingress accidents requires a primary loop or systems code that can switch from main loop cooling with $n$ loops, to n-1 loops, or to auxiliary loops. STG isolation (feedwater cut-off) must be modelled, and rellef valve discharge to the RB must be included. For the air ingress accidents primary loop forced flow cooldown under depressurized conditions must be included.

To assess the graphite oxidation and core FP release conditions, the in core heat and mass transfer with simultaneous chemical reactions has to be modelled in some detail.

\subsubsection{Avallable Tools for Accidents with Significant Graphite Oxidation}

The main tools for in-core analysis of energy, mass transport and chemica1 reactions are the GA code OXIDE-3 $[36,37]$ and the KFA code REACT/THERMIX [38]. Both codes can handle some of the required thermohydraulics analysis for the primary loops internally, but require some boundary conditions from separate analyses. They both consider the in-core effects in detail, OXIDE-3 for a prismatic core, and REACT/THERMIX for a pebble-bed core.

The codes will be described separately below with a comparison to follow. The major code features will be summarized and compared later in Table 3.3-1 (see Section 3.5). 


\subsubsection{OXIDE-3}

The OXIDE-3 code was developed by GA for prismatic fuel in 1974 [36] and has been applied to various water ingress accident scenarios [37]. It was reviewed by BNL in 1978 [39].

It considers the in-graphite diffusion of gases in significant detail and uses Langmuir type reaction kinetics equations with considerable curve fits to the best available data. Change of these models as better data become available is straightforward and some more recent data (for instance [45]) should be incorporated as applicable in future code applications.

In air ingress $0 X I D E-3$ considers only the heterogeneous reaction:

$$
\mathrm{C}+\frac{1}{2} \mathrm{O}_{2} \rightarrow \mathrm{CO}
$$

rather than considering the more general form

$$
\mathrm{C}+\mathrm{xO}_{2} \rightarrow \mathrm{yCO}+\mathrm{z} \mathrm{CO} 2
$$

with subsequent Boudouard reaction

$$
\mathrm{C}+\mathrm{CO}_{2} \rightarrow 2 \mathrm{CO}
$$

as well as the homogeneous reaction

$$
\mathrm{CO}+\frac{1}{2} \mathrm{O}_{2}+\mathrm{CO}_{2}
$$

Recent work using the THERMIX/REACT code [34] appears to indicate that all oxygen may be consumed by reaction (3.3.2) early in the core, with the Boudouard reaction $(3.3 .3)$ causing more graphite oxidation in later, hotter regions of the core.

Similarly OXIDE-3 only uses the graphite/steam reaction,

$$
\mathrm{C}+\mathrm{H}_{2} \mathrm{O}+\mathrm{CO}+\mathrm{H}_{2}
$$

disregarding the homogeneous water shift reaction

$$
\mathrm{CO}+\mathrm{H}_{2} \mathrm{O} \rightarrow \mathrm{CO}_{2}+\mathrm{H}_{2}
$$

The in-graphite diffusion model is detailed but strictly tailored to prismatic fuel. The chemical reaction kinetics allow for some catalytic effects and for burn-off effects. The ultimate results, in principle, permit not only the determination of total graphite burn-off, but also the depth profile of burn-off. For instance, the code applications of Ref. 37 indicate significantly higher burn-off of graphite inside the fuel matrix than in the web of the fuel element block due to increased chemical reactivity in the fuel region. The accuracy of these local predictions will, of course, strongly depend on the quality of the constants and functions used in the kinetics equations as well as the diffusion coefficients. 
The code does consider fuel hydrolysis in significant detail. This effect will apparently cause increased release of noble gases from damaged fuel particles.

For such detailed presentation of the core and some connected components, it is not practical to include all other primary loop components with equal detail. In addition to the core model, the code includes upper and lower plenum models as well as a relief valve discharge to the RB with some mode1ling of mass accumulations and combustibility conditions in the RB. However, other parts of the primary loop are not modelled, and inlet flows and temperatures for the inlet plenum must be prescribed as functions of time. Similar$1 \mathrm{y}$, the steam or air ingress rates must be prescribed. GA used the codes, TAP and FLASH, for these purposes, but other codes could be used here as well (see Sect. 3.2).

The code does permit a very fine core nodalization of up to 3,200 nodes and retains fairly fast execution time. The problem areas identified in the BNL review [39] were relatively minor:

The review identifies accident ranges (predominantly at high temperatures) where the current nodalization of the symmetry triangle may be insufficient for accurate results. The resulting possible inaccuracies may not be consequential but the user should be aware of them.

Failure to include the core support blocks in the analysis can induce errors, in particular, in the coolant impurity levels.

Better models for RB combustibility checks and for noble gas release from fuel hydrolysis were suggested.

Several coding errors were corrected and an improved time step algorithm was implemented.

\subsubsection{REACT/THERMIX}

The REACT/THERMIX code was developed by KFA [38]. It essentially uses the THERMIX code, developed for thermohydraulics of pebble bed cores, and adds a set of subroutines for chemical reactions. Radial convection of heat and mass is allowed via dispersion, and gas radiation is included in the model. The Lewis analogy is used in computing mass transfer between coolant and solids.

The code documentation and several related papers $[34,40,41]$ give a lucid description of three graphite oxidation regimes, depending on the interaction of diffusion and chemical reaction within graphite. At low temperatures (typically $<600 \mathrm{c})$ the reaction kinetics are limiting, in an intermediate range the in-pore diffusion is limiting, while at high temperatures (typically > 1200C) the in-coolant boundary layer diffusion limits the graphite oxidation. Following this outline a detailed diffusion and chemical reaction model is not used, but an "empirical relation" is used to compute the graphite oxidation, essentially as surface oxidation, i.e., REACT is not capable of describing graphite burn-off as a function of depth into the graphite. 
In the current form, the code also only deals with average burn-off around a pebble, while due to the expected strong variation of boundary layer thickness around a pebble, actual burn-off could be highly non-uniform. Reference 38 mentions an experiment series in progress (SUPERNOVA) to establish the experimental data for the above empirical relation and to assess whether non-uniform burn-off around pebbles is of concern.

While the diffusion and kinetics models are less detailed than those of OXIDE-3, REACT does include the following heterogeneous chemical reactions for air, steam and graphite:

$$
\begin{aligned}
& \mathrm{C}+\mathrm{x} \mathrm{O}_{2} \rightarrow \mathrm{yCO}+\mathrm{z} \mathrm{CO}_{2} \\
& \mathrm{C}+\mathrm{H}_{2} \mathrm{O} \rightarrow \mathrm{CO}+\mathrm{H}_{2} \\
& \mathrm{C}+\mathrm{CO}_{2} \rightarrow 2 \mathrm{CO}
\end{aligned}
$$

and the following homogeneous reactions:

$$
\begin{aligned}
& 2 \mathrm{CO}+\mathrm{O}_{2} \rightarrow 2 \mathrm{CO}_{2} \\
& 2 \mathrm{H}_{2}+\mathrm{O}_{2} \rightarrow 2 \mathrm{H}_{2} \mathrm{O} \\
& \mathrm{CO}+\mathrm{H}_{2} \mathrm{O} \rightarrow \mathrm{CO}_{2}+\mathrm{H}_{2}
\end{aligned}
$$

For the homogeneous reactions the kinetic expressions are given in terms of departure from thermodynamic equilibrium, which is computed separately.

The code does not consider any fuel hydrolysis reactions between $\mathrm{UC}_{2}$ and $\mathrm{H}_{2} \mathrm{O}$ nor any consideration of fission product release from fuel or graphite. A statement is made that even if the fuel particle graphite coatings were to be weakened by oxidation, that the silicon carbide coating would be oxidized to $\mathrm{SiO}_{2}$ and would "retard" additional attacks [34].

The steam inflow into the primary loop has to be prescribed as a function of time. The transient in the remainder of the primary loop beyond the core has to be obtained from a separate code. For instance, THERMIX with LOOPY could be used. In one of the early applications [42], COBRA was mentioned as such a boundary condition code, even though it is not clear how COBRA could be used in this context.

In principle, one could couple REACT with current THERMIX versions which apparent1y have loop capabilities and thereby avoid the requirement to run separate codes for primary loop boundary conditions.

Separate code applications for air ingress with auxiliary loop cooling $[34,43,44]$ generally indicate that fuel temperatures are only raised slightly due to local burning, at most reaching $1200 \mathrm{C}$ for a core with $1000 \mathrm{C}$ design temperature. Thus, fuel fallure from excessive temperature is not to be expected. With auxiliary cooling the oxidation stops after 4 to $96 \mathrm{hrs}$, depending on the assumed air ingress rate and the number of loops operating. The maximum burn-off (averaged over a pebble) ranges from 100 to $350 \mathrm{mg} / \mathrm{cm}^{2}$, which represents about 10 to $40 \%$ of the total exterior graphite coating of the fueled pebbles. (It should be noted that the higher values are obtained for extremely large assumed air ingress rates, which may not be realistic.) 
A typical water ingress application into a 500 Mwe pebble bed reactor [42] uses about $4000 \mathrm{~kg}$ of water ingress with auxiliary loop cooling, resulting in total graphite oxidation of 600 to $1500 \mathrm{~kg}$ of graphite with a maximum pebble surface burn-off of $36 \mathrm{mg} / \mathrm{cm}^{2}$. The oxidation is terminated after about 2.5 hrs.

\subsubsection{Comparison of OXIDE-3 and REACT/THERMIX}

The two codes present the only available analysis tools for the important chemical reactions during ingress accidents. While OXIDE-3 was developed about 12 years ago for prismatic fuel, REACT/THERMIX is about 7 years old and was designed for a pebble-bed core.

The most important code features are compared in Table 3.3-1.

The differing fuel arrangement requires quite different fluid flow as we11 as convective heat and mass transfer modelling. Beyond this, there are other significant differences.

The diffusion and chemical reaction kinetics models of OXIDE-3 are much more detailed than those of REACT/THERMIX and permit, in principle, a prediction of burn-off distribution normal to the coolant flow direction. This is, for instance, important if fuel graphite has a higher chemical reactivity than the graphite of the fuel element web or of the outer fuel pebble coating. How valuable this detail is depends also on the availability of reaction kinetics and diffusion data for the specific graphite being used. On the other hand, even for very pessimistic assumptions, the observed burn-off rates have remained small even when the reaction rates were artificially raised by a factor of $10[37]$.

The oxidation rates of REACT/THERMIX averaged over pebble surfaces may not be good enough, since good arguments can be made for local variation of burn-off around the pebble surface. Further information from current (or recently concluded) KFA experiments might permit further insight in this area.

For carbide fuels, the hydrolysis reaction and the ensuing release of noble gases cannot be disregarded. On1y OXIDE-3 considers this effect.

On the other hand, REACT/THERMIX considers separately the primary burning of graphite and oxygen to $\mathrm{CO}$ and $\mathrm{CO}_{2}$ with subsequent secondary conversion of $\mathrm{CO}_{2}$ with graphite to $\mathrm{CO}$, while OXIDE-3 only considers the reaction of graphite and $\mathrm{O}_{2}$ to $\mathrm{CO}$. Recent applications of REACT for air ingress accidents appear to indicate that the primary reaction begins in a relatively short and cooler region of the core, consuming all available oxygen, with the secondary (Boudouard) reaction extending over a wider downstream region of the core [34]. Thus, the treatment of all reactions, as done in REACT may be preferable.

Some fission product release computations are included in OXIDE-3, as is a simple model of the helium purification system.

Both codes deal with the core and plena only, including some blowdown modelling to the RB. But, core inlet flow and temperatures must be obtained fro $_{m}$ other systems codes which are not designed for the ingress of $\mathrm{H} 2 \mathrm{O}$ and/or 
air. Similarly, the steam inflow as well as the air ingress are prescribed as functions of time. A merger of REACT with the current THERMIX code could eliminate most of these difficulties but this would not be a trivial task. There have been no reports indicating that this has been done.

Table 3.3-1 Comparison of Ingress Accident Codes OXIDE-3 and REACT/THERMIX

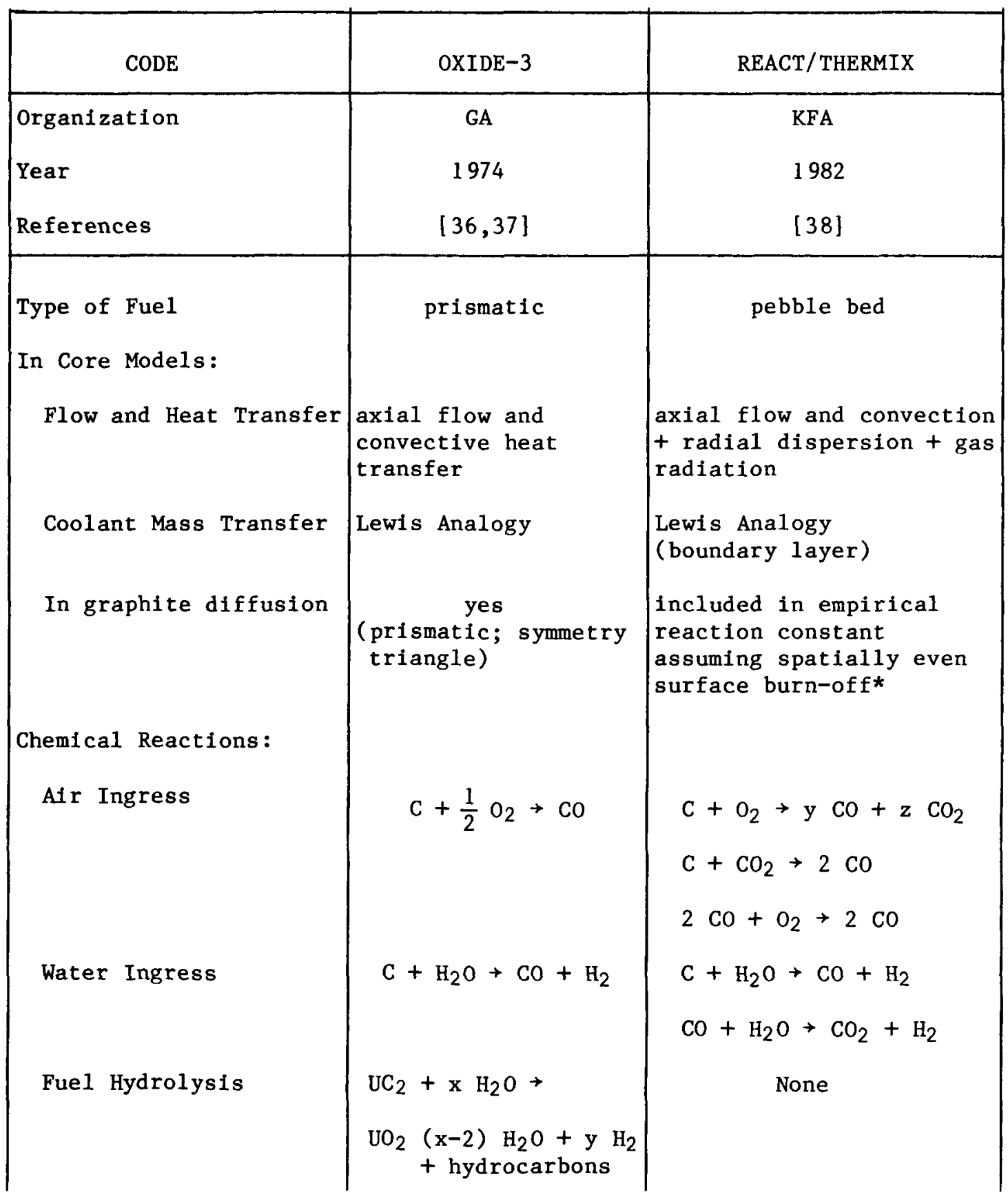


Table 3.3-1 (cont.)

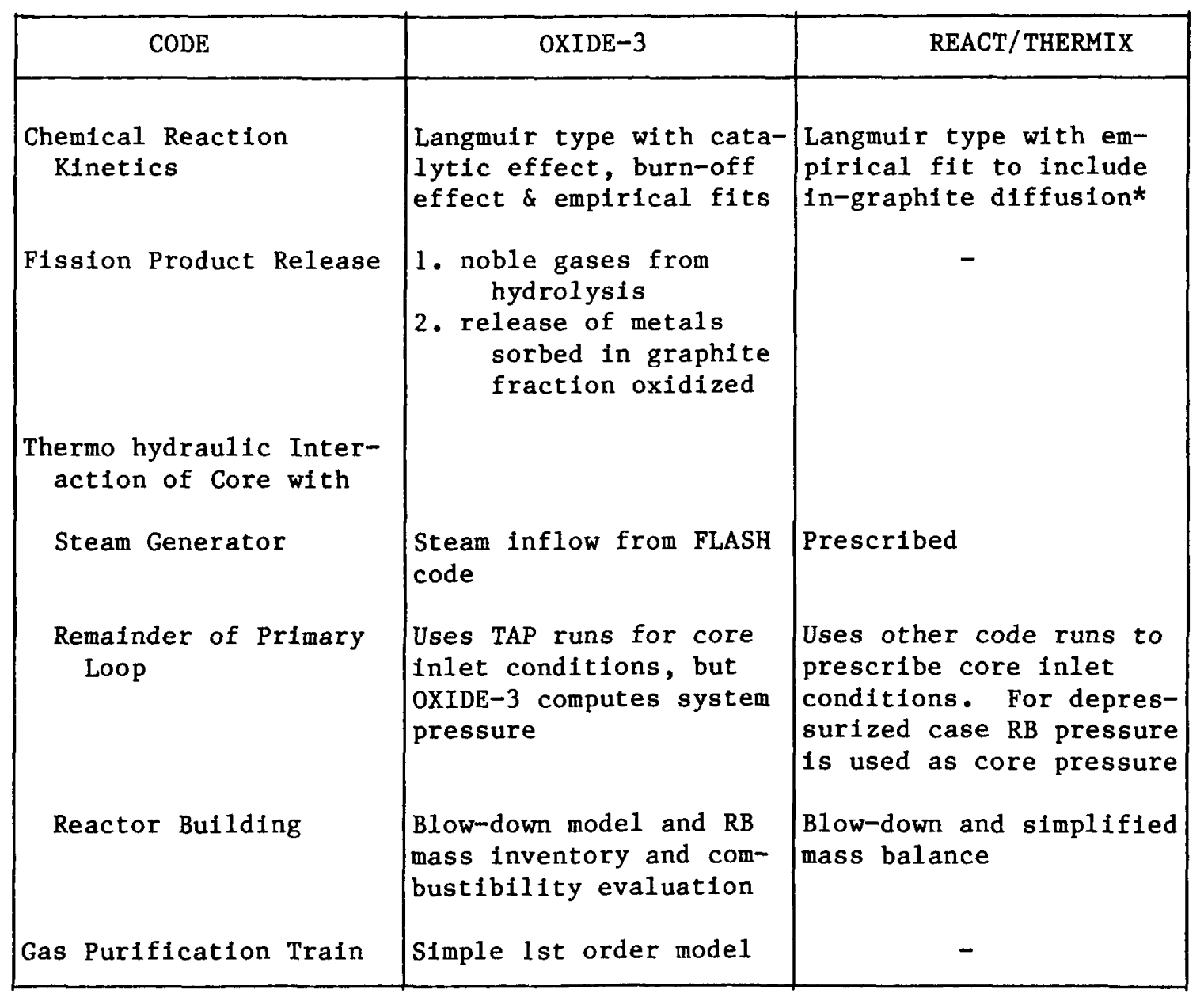

*KFA refers to experiments in progress for verification and justification of these simplifications. 


\subsubsection{Reactivity Transients}

For undermoderated cores another consequence of concern during water ingress accidents could be a reactivity increase with a corresponding power increase. Questions to be investigated are:

1. whether the action of the shutdown and/or reserve shutdown systems are fast enough, and

2. whether in cases of the failure of the shutdown system the resulting power excursion could lead to significant fuel temperature rise and fuel failures.

One such investigation for pebble-bed reactors is reported in Reference 35. The series of codes used for this work by KFA are:

COROX for the primary loop thermohydraulics of a 1-dimensional primary loop with a prescribed source flow.

SIKAN-E a dynamic steam generator program, and

SHOVAV-JUEL a detailed 1-dimensional transient neutron kinetics code which is a KFA modified version of an original liquid-cooled reactor code.

The three codes were apparent1y run iteratively for several cases of water ingress accidents. A steam inflow model based on outputs of SIKAN-E was incorporated into SHOVAV-JUEL. Apparent1y COROX can determine the graphite corrosion rate, but no details of the chemical reaction and/or diffusion model are given. For the relatively short reactivity transients of less than 100 s the amount of graphite corrosion is less of a concern than the resulting pressure increase due to increase of the gas volume with the reaction. However, that effect was found to be small compared to the effect of the reactivity transient on the system pressure.

The results appear to indicate that even massive water ingress rates -break of all steam generator tubes resulting in $55 \mathrm{~kg} / \mathrm{s}$ ingress up to a total of 4 tons of water, plus assuming no lift off of the safety valves - resulted in a significant short power excursion of up to $180 \%$ with a subsequent power drop and a maximum fuel temperature increase of only $120 \mathrm{C}$.

Nevertheless, the investigation of such transients will be required during the licensing process, even though it is expected that these transients would only be of significant interest at a later date. While we know little of the above three codes, the MINET code described in Section 3.2 can readily be adapted to perform the functions of COROX, SIKAN-E and the steam ingress model of SHOVAV-JUEL, while the point kinetics model suggested in Section 3.2 could be used in place of the SHOVAV-JUEL kinetics model. MINET would have to be modified by providing the properties for a He $-\mathrm{H}_{2} \mathrm{O}$ mixture as primary coolant (He and $\mathrm{H}_{2} \mathrm{O}$ by themselves are among currently allowed properties), and some code testing regarding the use of a valve (break) between the primary and secondary loops might be required. The code does not include the effect of gas formation due to corrosion, but this effect was found to be small in Ref. 35. If desirable, a simplified gas-source term for this effect could be 
modelled, but detailed graphite corrosion modelling as found in OXIDE-3 or REACT would certainly not be cost-efficient for such applications. The MINET modifications mentioned here could be achieved within 6 man months, assuming that the 1-dimensional core model and the point kinetics model suggested in Section 3.2 have been provided.

\subsubsection{Secondary Side Escape of Primary Coolant}

As the secondary side pressure generally exceeds the primary 1oop pressure, helium escape through the secondary system is generally not possible. One scenario that has been considered in connection with steam generator tube breaks is as follows: subsequent to a steam generator tube break the moisture monitors activate scram, and isolation and dump of the defective steam generators. If the feedwater side isolation valve were to remain open, the continuing supply of feedwater could result in liquid water reaching the secondary side safety valve, causing it to fail in the open position, since these valves are not designed for liquid flow. With the preceeding ingress of water into the primary loop, some of the Cesium from the circulating inventory deposited in the steam generator could have been dissolved by the steam, and could now escape with the primary loop $\mathrm{He} / \mathrm{H}_{2} \mathrm{O}$ mixture through the failed secondary side safety valve to the environment.

The logical code to apply for such scenarios would again be MINET, with $\mathrm{He} / \mathrm{H}_{2} \mathrm{O}$ mixtures previously having been added to the code. The thermohydraulics through the partly flooded failed heat exchanger might require some special consideration, but the same would apply for any other code to be used for such transients. Whether and how much additional code development would be required for this task is not clear at this time. The previously suggested modifications would most likely also apply for these transients, except for possible flow of the steam mixtures through subcooled water, which is a separate problem, that most 1 ikely will not have to be modelled.

\subsubsection{Recommendations}

At this time, DOE has not committed itself to prismatic or pebble bed fuel, even though pebble bed concepts appear to be leading.

Should the US effort retain the prismatic fuel, then a code like OXIDE-3 could be updated covering some of the points from the BNL review [39], as well as changing reaction and diffusion data based on current graphite types and latest information available, plus an addition of the Boudouard reaction and the homogeneous gas reactions. Furthermore, one should at that time, consider coupling OXIDE-3 with some systems code like MINET, to avoid the cumbersome and generally unsatisfactory use of boundary condition code runs.

Should the U.S. effort shift to pebble bed fuel, one should assess how best to combine the diffusion and reaction kinetics models of OXIDE- 3 with the core thermohydraulics of the REACT/THERMIX package. As we are not completely sure of the latest status of REACT/THERMIX it is not possible, at this time, to fully assess the options in this area.

The overall recommendation in this area is, to currently ascertain whether any more advanced REACT/THERMIX versions are available, and to develop a plan on how to proceed if pebble bed fuel becomes the US design. However, any 
actual code modifications or preparations should be deferred until a design decision has been made.

For the analysis of reactivity transients, the use of MINET with some modifications for helium $/ \mathrm{H}_{2} \mathrm{O}$ mixtures is recommended. The MINET modifications are estimated to require approximately 6 man months. If coupling of MINET with a fairly detailed l-dimensional neutron kinetics program should eventually become desirable, further work would be required. Recommendations in this area will be made then.

For secondary side escape of primary coolant, MINET can again serve well, and the previously suggested code modifications (Improved 1-dimensional core mode1, $\mathrm{He} / \mathrm{H}_{2} \mathrm{O}$ mixture properties, and modelling of a flow connection between primary and secondary loop path) appear to apply for such transients.

\subsection{Containment/Confinement Atmosphere}

The CNTB7 code was developed by GA for short term containment atmosphere transients (blowdown and several hours). The OXIDE-3 code, by GA, also includes some modelling of the reactor building atmosphere during ingress accidents. For long term core heatup transients (days) GA developed CARCAS*, while ATMOS was developed at BNL as part of the source term study (see also Section 3.1).

In considering some of the features of the CNTB7 code, it immediately became apparent that some of 1 ts features would be valuable additions to the OXIDE-3 containment section and to the ATMOS code. Since ATMOS is an NRC sponsored code, the more useful features of CNTB7 should be considered for inclusion in order to arrive at a single NRC sponsored code which can handle blowdown transients, intermediate length transients, and long term core heatup transients for containment type as well as confinement type RBs.

The major features of the three codes are compared in Table 3.4-1. The most important advantage of CNTB7 is that it permits transient heat conduction into a large number of specified structures of different dimensions, ordered by elevation. Since the RB atmosphere temperature is largely controlled by the conductances of these structures, such a feature is very valuable in situations where enough details about the RB internal components are known. On the other hand, for fast transients (few hours), only small parts of the RB walls or PCRV concrete will participate, and the even nodal spacing used in CNTB7 can be either inefficient or provide for inaccurate results. The ATMOS code uses a non-even node spacing, controlled by a user specified spacing parameter. Its transient conduction routine is set up for application to multiple structures, but only a single one is currently being provided for. An extension of ATMOS in this area will be of great value later, when RB design details are available. However, as other improvements to ATMOS are suggested to be done now, it is recommended to include this feature at this time.

It should be noted here, that the OXIDE-3 solid conduction treatment is extremely rudimentary and does not solve a transient 1 -dimensional conduction problem. As pointed out in the documentation [36], this approach will tend to

*as noted In Section 3.1, almost nothing is known about CARCAS. 
Table 3.4-1 Comparison of Containment Atmosphere Models

\begin{tabular}{|c|c|c|c|}
\hline Code & CNTB 7 & OXIDE-3 & ATMOS \\
\hline $\begin{array}{l}\text { Originator } \\
\text { Original purpose }\end{array}$ & $\begin{array}{l}\text { GA } \\
\text { blowdown and subse- } \\
\text { quent transient }\end{array}$ & $\begin{array}{l}\text { GA } \\
\text { gas exchange during } \\
\text { ingress accidents }\end{array}$ & $\begin{array}{l}\text { BNL } \\
\text { long term core } \\
\text { heatup scenarios }\end{array}$ \\
\hline $\begin{array}{l}\text { Primary Loop to } \mathrm{RB} \\
\text { flow }\end{array}$ & $\begin{array}{l}\text { prescribed input or } \\
\text { computed from given } \\
\text { const core condi- } \\
\text { tions }\end{array}$ & $\begin{array}{l}\text { integral core to RB } \\
\text { flow model with } \\
\text { changes in core and } \\
\text { CB states fully } \\
\text { considered }\end{array}$ & $\begin{array}{l}\text { const } p \text { between } \\
\text { cavities }\end{array}$ \\
\hline RB out $f 1$ ow & $\begin{array}{l}3 \text { types of } C B \text { leak- } \\
\text { age plus ventila- } \\
\text { tion system }\end{array}$ & $\begin{array}{l}\text { leakage prescribed } \\
\text { fct of } \Delta p\end{array}$ & $\begin{array}{l}\text { leakage pre- } \\
\text { scribed fct of } \\
\text { density }\end{array}$ \\
\hline $\begin{array}{l}\text { Applicable to } \\
\text { confinements }\end{array}$ & yes & (no) & no \\
\hline $\begin{array}{l}\text { Ventilation system } \\
\text { details }\end{array}$ & yes & no & no \\
\hline Gas mixing in $\mathrm{CB}$ & partial or complete & complete & complete \\
\hline CB atmosphere & $\begin{array}{l}1 \text { for mixed gas } \\
1 \text { for unmixed gas }\end{array}$ & uniform & uniform \\
\hline $\begin{array}{l}\text { Gas components in } \\
\text { mixture }\end{array}$ & He, air & $\mathrm{He}, \mathrm{CO}, \mathrm{H}_{2}, \mathrm{H}_{2} \mathrm{O}, \mathrm{CO}_{2}$, air & $\begin{array}{l}\mathrm{He}, \mathrm{CO}, \mathrm{H}_{2}, \mathrm{H}_{2} \mathrm{O} \\
\mathrm{CO}_{2}, \text { air }\end{array}$ \\
\hline Combustion & no & $\begin{array}{c}\text { yes } \\
\text { (simplified) }\end{array}$ & $\begin{array}{l}\text { checks on } \\
\text { flammability }\end{array}$ \\
\hline $\begin{array}{l}\text { Heat transfer to } \\
\text { solid structures }\end{array}$ & $\begin{array}{l}\text { many separate tran- } \\
\text { sient conduction } \\
\text { bodies }\end{array}$ & $\begin{array}{l}\text { non-transient, over- } \\
\text { simplified (general- } \\
\text { ly overpredicts gas } \\
\text { temperatures) }\end{array}$ & $\begin{array}{l}\text { single transient } \\
\text { conduction model }\end{array}$ \\
\hline Condensation & no & $\begin{array}{l}\text { Thermodynamic } \\
\text { equilib }+ \text { simplified } \\
\text { wa11 condensation }\end{array}$ & $\begin{array}{l}\text { Thermodynamic } \\
\text { equilibrium }\end{array}$ \\
\hline $\begin{array}{l}\text { Heat transfer } \\
\text { correlations }\end{array}$ & natural convection & natural convection & $\begin{array}{l}\text { natural convec- } \\
\text { tion }+ \text { gas ra- } \\
\text { diation }\end{array}$ \\
\hline Gas properties & $\begin{array}{l}\mu, k=f(T) \\
C_{v}, C_{p}=\text { const }\end{array}$ & ( constant) & $\begin{array}{l}\text { al1 temperature } \\
\text { dependent }\end{array}$ \\
\hline
\end{tabular}


underpredict the heat flow to the walls and thereby overpredict the containment atmosphere temperatures.

As ATMOS was intended for long term transients, its current initial state is based on equalized pressure between reactor and $R B$, with the helium from the core and the original air fully mixed, without any "prior" energy loss to the solid structures (1.e., the pressure equalization during blowdown is assumed to occur without any heat transfer from the $\mathrm{CB}$ gas to the solid structure). For short term transients, as for slow blowdown, this approach is not satisfactory. CNTB7 permits either a prescribed time dependent core to CB flow, or computes such a flow assuming constant prescribed reactor gas temperature during the blowdown period.

The OXIDE-3 blowdown flow model is clearly preferable, since it is used in a code which tracks both, the primary loop atmosphere and the CB atmosphere. All other codes, core codes as well as RB codes, have the condition on one side usually prescribed as boundary condition. The OXIDE-3 flow model includes isothermal pipe flow to an orifice (break or rellef valve opening), and isentropic compressible critical or subcritical flow across the orifice, depending on the pressure ratio. While it is not clear whether this isothermal assumption on the pipe flow is necessarily good, the overall model is more satisfactory than that of any other code. It also allows back flow after initial pressure equalization.

As ATMOS is an RB code, it cannot use the full OXIDE-3 approach. However, as core temperatures are now a time dependent input to ATMOS, it is suggested to incorporate the options of a pipe plus orifice model with pipe inlet temperatures being the prescribed core temperatures and pipe inlet pressure being the core pressure, computed from the remaining core gas inventory. As a separate option, a user prescribed time dependent core to RB flow could also be provided.

While ATMOS and OXIDE-3 assume a completely mixed RB atmosphere, CNTB-7 permits some prescribed fraction of the original air to remain unmixed, this user specified fraction remaining constant. Such an option, even though an idealization, does permit parametric evaluation of the effect of mixing. It is recommended to implement a similar option in ATMOS. However, since it covers longer transients, we would prefer to extend this option to permit the unmixed fraction to decrease with time. It does not appear that this enhancement would present great difficulty.

The RB outflow in CNTB7 is due to leakage and/or through the ventilation system, with highly detailed ventilator performance codings. It is suggested to include into ATMOS some of these features, namely the option of an open RB with lag times for the closing of valves. These suggestions were essentially already made in Section 3.1, to modify ATMOS for confinement type RBs.

It is not apparent at this time why detailed ventilator performance characteristics as given in CNTB7 would significantly affect the major results, i.e., the $R B$ pressure and temperature as well as the gas release from the $R B$ to the atmosphere. We will evaluate whether such an addition is essential and make corresponding recommendations. 
The ATMOS code checks for the formation of combustible mixtures in the RB. The OXIDE-3 code goes one step further and includes simple combustion computations. CNTB7 has neither of these features. Even though we do have a separate combustion program, which in principle could be incorporated into ATMOS, it does not appear to be essential or cost effective at this time, since we do not anticipate the accumulation of significant amounts of combustibles in the RB for the most likely accident scenarios. We recommend to retain our checks on $f l a m m a b i l i t y$, but to incorporate our combustion routines into ATMOS only if such a need should arise at a later time.

The RB heat transfer correlations of ATMOS include the effect of gas radiation, which the other codes do not. Its gas property features are also more advanced than those of the other codes.

OXIDE-3 models condensation in a slightly better way than ATMOS. In addition to bulk condensation maintaining thermodynamic equilibrium wall condensation is permitted with a rather simplified model. However, since such wall condensation could indeed reduce the $\mathrm{H}_{2} \mathrm{O}$ concentration of the CB atmosphere below the saturation level, it would be a desirable feature for ATMOS, which currently bases its condensation rate on thermodynamic equilibrium. We suggest to include a surface condensation model applying some of the more recent LWR related work for this purpose $[46,47]$.

To summarize, the following improvements for ATMOS have been suggested:

1. Modify gas release to environment to simulate containment and/or confinement (also Section 3.1).

2. Permit gas sources inside $R B$ for simulation of concrete degradation in core heatup transients without RCCS (was mentioned as non-urgent in Section 3.1).

3. Extend the transient conduction model to handle several solid RB structures, permitting a more detailed description of actual RB conditions.

4. Provide an improved blowdown model.

5. Permit partial mixing of RB gases for parametric evaluation.

6. Investigate importance of detalled modelling of ventilation system.

7. Improve condensation model.

Point 2 may not be essential, at least not in the near future. To fully utilize the advantage of point 3 , one would have to know more about RB design details. However, neither option is difficult to implement, and it is more cost efficient to include these now.

It is estimated that all these improvements could be implemented in about 6 man months. This would then provide us with a single code for all RB transients, from short term blowdown to long term core heatup, including confinement as well as containment structures. 
As a sideline, it should be mentioned that the CNTB7 code is not well suited for wide applications, since it has been programmed in a very awkward form. It consists of one program of about 1200 lines without any breakdown into subroutines. Its variable names are highly nondescriptive and the same variable name may be used for completely different variables. The coding is very hard to follow. However, with the above suggestions, ATMOS would incorporate all features of value for short and long term analyses, and there would then be no need for CNTB7 in future licensing efforts.

\subsection{Neutronics}

While detailed neutronics capabilities will be required in the licensing process, the area has not been perceived as one of the most urgent ones. A detailed review on needs and capabilities in this area will be provided at a later date.

For pebble-bed cores, the detailed VSOP package developed by KFA and avaflable in the U.S. at MIT would most likely be a first candidate. However, computer runs times to establish an equilibrium core are apparently quite lengthy. 
In Section 3, the major accident scenarios, the phenomena to be modelled and the codes currently available for this work have been described. In this Section, we will provide a summary and emphasize the work that we have identified thus far as remaining to be done in order to provide efficient support for future NRC 1icensing efforts. Based on the history of the HTGR, most U.S. codes were directed towards prismatic cores. Currently, the pebble-bed core is a leading contender, and a large part of this report is, therefore, directed towards pebble-bed cores.

\subsection{Depressurized Core Heatup Scenarios}

Most major hypothetical fission product release scenarios arise from long term depressurized core heatup accidents. The analysis of the thermohydraulics of the reactor during such accidents is fairly straightforward, primarily requiring a conduction and radiation heat transfer analysis of the reactor assembly to determine the critical component temperatures. The THATCH code serves for this purpose, and the future needs would be mainly better thermal conductivity data for the core, and possibly other properties, once specific material selections have been made. The THERMIX code could be applied here, too, but our current codes are at least as good for such transients, and most likely, more efficient. (If future concepts should return to PCRV designs with high power densities, some additional modelling of concrete and steel component melting should be resumed.)

After depressurization, the gas exchange between the reactor vessel and the reactor building ( $R B)$, be it of confinement or of containment type, will have to be evaluated. For this purpose the ATMOS code is avallable, although it does require some modifications, extending it to cover confinement type RBs. Also, some more detalls in the modelling of heat conduction to internal structures, and including the effects of $\mathrm{RB}$ concrete degradation in case of RCCS fallure, would be desirable. All of these could be provided with an effort of about 3 man months.

In core heatup accidents in modular HTGRs, the reactor cavity cooling system (RCCS) plays a crucial role. The design is in many ways similar to the liner cooling system (LCS) of previous designs. The LINER codes developed for LCS analyses and the MINET code could be applied to RCCS performance analyses, but any modifications required can only be suggested once design details are avallable and specific problems have been identified.

In current low power density designs, hardly any fuel fallures are anticipated, even in the worst possible accidents. Therefore, very simple upper bound analyses can be used to show that the fission product release from the reactor remains minor. Nevertheless, eventually some modelling of FP releases during such scenarios will be required. As first step for this, primary system natural clrculation flows would be required. Our current capabilities using THATCH are sufficient for prismatic cores, and for 1-dimensional natural convection flows in pebble-bed cores. For multi-dimensional natural convection in pebble-bed cores, THERMIX or NAKOGAS could be applied or - if these are not avallable -- new models would have to be developed. Regarding the 
fission product release by diffusion and convection, some previous models are available (SORS, FRESCO), and an evaluation of these will be provided at a later time.

\subsection{NSSS Transients with Convective Heat Removal}

The large majority of the transients to be considered during licensing efforts will fall into this category. Even though many of these remain rather mild they are important in assessing the safety of the system, and they are also often the precursors of potential severe accidents.

For general 1-dimensional modelling of primary loop transients under forced flow conditions or for pressurfzed natural circulation, several codes were found to be available. Most of these systems codes were originally developed for prismatic fuel cores and specific primary loop configurations with relative1y little flexibility to represent diverse systems. The exception is the MINET code, which was originally developed to permit assembly of a wide variety of plant components in any desired configuration. At this time it lacks a detailed HTGR core module, but can represent all other primary loop components, including steam generators, with ease. Its component modules have a significant validation base [22-26]. Since a one-dimensional core model is relatively simple, it was found to be the best alternative to develop a 1-dimensional core module for either prismatic or pebble-bed cores and use MINET with this module for a large variety of primary loop transients. It was estimated that such a core module can be made operational with 5 man months. For applications requiring significant pebble-bed detail, including spatial temperature profiles in representative spheres, the THERMIX code could be applied when it becomes avallable.

For very rapid blowdown transients, the use of a local transient moment um equation can become important. This could be done with the RATSAM code. Even though this code has been reviewed and modified by us, it was not applied to such transients by us yet, and a brief review for such cases of about 2 man months would be recommendable.

For multi-dimensional pebble-bed core flow transients -- if they are required in the currently considered small cores with pebble recirculation (MEDUL cycle) -- the THERMIX code would be a possible tool, as would NAKOGAS, which is even more detailed (although probably expensive to utilize). If these codes should not be available, a variant that has been used is the application of COBRA to multi-dimensional pebble-bed cores. As MINET appears to have the most flexibility in presenting the primary loop, a combination of a selected multi-dimensional core model combined with MINET representing the loop could be an efficient choice. No immediate need for multi-dimensional core representations is seen at this time, and a further assessment at a later time is suggested.

For most ATWS transients, simple point kinetics would appear to be sufficient and a combination of MINET with the above suggested 1-dimensional core module and some point kinetics should provide adequate coverage of most needs. To provide the kinetics capabilities, about 2 man months are required. 
For multi-dimensional prismatic fuel cores in conduction transients and with forced flow, ORECA is the avallable tool.

\subsection{Ingress Scenarios}

During accidental air and/or water ingress, the primary concern is for graphite oxidation with potentially raised fuel temperatures and fission product releases from graphite burn-off as well as from chemical reactions between carbide fuels and $\mathrm{H}_{2} \mathrm{O}$. The available codes OXIDE-3 and REACT/THERMIX were compared. OXIDE-3 is strongly oriented towards prismatic fuel, has a more detailed reaction kinetics and diffusion model and includes fuel hydrolysis. REACT/THERMIX is a pebble-bed code with less detailed oxidation kinetics, but considering a greater variety of chemical reactions. At this time, it is suggested to hold off until a decision for a lead plant has been made in the DOE/industry program. Thereafter, one should concentrate - depending on the above decision - on which code is more desirable and most likely modify that code to incorporate the more desirable features of the alternate code.

For reactivity transients in connection with water ingress, the MINET code could serve as a basis after modifications, primarily providing for $\mathrm{He} / \mathrm{H}_{2} \mathrm{O}$ mixtures and for flow between primary and secondary loop. The effort required for these modifications is about 6 man months. This would be done in conjunction with the above point kinetics model of Section 4.2. If 1-dimensional kinetics are later found to be essential, this would require further work.

The potential secondary side escape of primary loop coolant, subsequent to steam generator break, through a failed secondary side safety valve could also be done with MINET, and the above mentioned modifications would be sufficient to establish this capability.

\subsection{Containment/Confinement Atmosphere}

The maln code applied by GA for short term HTGR containment transients is CNTB7. It appears that if some of its features were incorporated into our long term ATMOS code, that ATMOS could become the general tool covering short, as well as, long term transients in containment or confinement atmospheres.

A series of improvements for ATMOS has been itemized in Section 3.4. These include a more detailed description of the very essential transient conduction to solid structures, an improved blowdown model, an extension to confinement type RBs and partially mixed atmospheres.

These improvements would require about 6 man months and would provide the capability to apply one code for all RB transients of short or of long duration, in confinement or containment type RBs.

\subsection{Neutronics}

Evaluation of the available neutronics codes will be provided at a later time. 


\section{REFERENCES}

1. V.S. Boger, E.J. Kohler, H.L. Gotscha11: "Ut11ity Evaluation of High Temperature Gas-Cooled Reactors," ANS/ENS International Conference, Washington D.C., November 1984 .

2. "Evaluation of Sma11 Modular High Temperature Gas-Cooled Reactors Applied to Electricity Generation," Bechte1 Group, May 1984, GCRA Report GCRA84002 .

3. GA presentation to ACRS, February 5, 1985.

4. "Interim Evaluation Report 4 x 250 MW(t) HTGR Plant Vertical-in-Line Steel Vessel Concept," Bechtel National, Inc. GCRA Report BNI/GCRA84-006, September 1984 .

5. H. Krohn, "Freisetzung von Spaltprodukten aus dem Core eines Kugelhaufenreaktors bei Stoerfallen mit Core-Aufheizung," Kernforschungsanlage Juelich GmbH, (ISSN 0366-0885), Jue1-1791, Juli 1982 .

6. R. Schulten, "Entwicklungstendenzen des HTR," Chemie des Hochtemperatur reaktors," Jue1-Conf-43, Pg. 5, November 1981 .

7. J.M. Dickey, "An Analysis of SORS: A Computer Program for Analyzing Fission Product Release from HTGR Cores During Transient Temperature Excursions," Brookhaven National Laboratory, BNL-NUREG-50806, Apri1 1978.

8. H.J. Reilly, et al., "Preliminary Evaluation of HTGR Severe Accident Source Terms," Idaho National Engineering Laboratory, EGG-REP-6565, Apri1 1984.

9. Peter G. Kroeger, "Assessment of HTGR Liner Cooling System Performance Under Accident Conditions," Brookhaven National Laboratory, BNL-NUREG33073, November 1983.

10. J.S. Gilbert, P.A. Secker, Jr., J.C. Vigil, M.J. Wecksung, and G.J.E. Willcutt, Jr., "User's Manual for the Composite HTGR Analysis Programs (CHAP-2)," Los Alamos Scientific Laboratory Report, LA-NUREG-6576-M, March 1977.

11. G.J. Van Tuyle, T.C. Nepsee, J.G. Guppy, "MINET Code Documentation," Brookhaven National Laboratory Report NUREG/CR-3668, BNL-NUREG-51742, February 1984.

12. J.C. Cleveland, R.A. Hedrick, S.J. Bal1, J.G. Delene, "ORTAP: A Nuclear Steam Supply System Simulation for the Dynamic Analysis of High Temperature Gas Cooled Reactor Transient," Oak Ridge National Laboratory Report ORNL/NUREG/TM-78, Sept . 1977.

13. R.K. Deremer and T. Shih, "RATSAM: A Computer Program to Analyze the Transient Behavior of the HTGR Primary Coolant System During Accidents," General Atomics Report GA-A-13705, May 1977. 
14. A. Bardia, et a1., "TAP: A Program for Analysis of HTGR Nuclear Steam Supply System Performance Transients," General Atomic Company Report GA-A13248, January 1976.

15. K. Peterson, K. Verfondern, H. Barthels, and J. Banaschek, "Thermal Hydraulics of the Pebble-Bed High Temperature Reactor Under Accident Conditions," Proc. 1st Int. Topical Meeting on Nuclear Reactor Thermal Hydrau1ics, Saratoga, NY, 1980 .

16. J.C. Cleveland, "CORTAP: A Coupled Neutron Kinetics-Heat Transfer Digital Computer Program for the Dynamic Simulation of the High Temperature Gas Cooled Reactor Core," Oak Ridge National Laboratory Report ORNL/NUREG/TM39, January 1977.

17. G. Gysler and H. Hague, "On the Thermal-Hydraulics of Pebble-Bed Reactors," Proc. 1st Int. Topical Meeting on Nuclear Reactor Thermal Hydraulics, Saratoga, NY, 1980, NUREG-CP0014, 1980.

18. A. Badur, R. Finken, I. Hofer, W. Klump, G. Meister, and W. Rehm, "NAKOGAS-1, ein Rechenprogramm zur Berechnung Instationarer Temperaturund Stromungsfelder in Kugelhaufen-Roadtoren bei Ausfall der Zwangskuhlung," Kernforschungsanlage Juelich, Jul-1528, Aug 1978.

19. S.J. Ball, "ORECA-I: A Digital Computer Code for Simulating the Dynamics of HTGR Cores for Emergency Cooling Analysis," Oak Ridge National Laboratory Report ORNL/TM-5159, NRC-8, Apri1 1976.

20. R.A. Hedrick and J.C. Cleveland, "BLAST: A Digital Computer Program For the Dynamic Simulation of the High Temperature Gas Cooled Reactor Reheater-Steam Generator Module," Oak Ridge National Laboratory Report ORNL/ NUREG/TM-38, NRC-8, June 1976.

21. K.R. Stroh, P.A. Secker, R.B. Lazarus, P.L. Rivera, "LASAN-2 A Genera1 Systems Analysis Code for Large-Scale Model Simulations," Los Alamos Scientific Laboratory, Draft report, 1982.

22. G.J. Van Tuyle, "MINET Validation Study Using Steam Generator Test Data," Proc. International Conference on Power Plant Simulation, Cuernavaca, Morelos, Mexico, Nov. 1984, also Brookhaven National Laboratory Report NUREG/CR-3813, BNL-NUREG-51775.

23. G.J. Van Tuyle, G. Slovik, E.G. Cazzoli, "RAMONA/MINET Composite Representation of BWR Therma1-Hydraulic Systems," to be presented at the Third International Meeting on Reactor Thermal Hydraulics at Newport, RI, October 1985.

24. G.J. Van Tuyle, "MINET Simulation of a Helical Coil Sodium/Water Steam Generator, Including Structural Effects," Brookhaven National Laboratory Report NUREG/CR-3765, BNL-NUREG-51766, Apri1 1984.

25. G.J. Van Tuyle, "MINET Validation Study Using EBR-II Transient Data," Second Proceedings of Nuclear Thermal Hydraulics Division, American Nuclear Society, New Orleans, LA., June 1984, also Brookhaven National Laboratory Report NUREG/CR-3603, BNL-NUREG-51733. 
26. G.J. Van Tuyle, J.G. Guppy, and T.C. Nepsee, "MINET - Transient Analysis of Fluid Flow and Heat Transfer Networks," Proc. of the 1983 International Computers in Engineering Conference and Exhibit, Chicago, IL, Aug. 1983.

27. J.C. Conk1in, "ORTURB: A Digital Computer Code to Determine the Dynamic Response of the Fort St. Vrain Reactor Steam Turbines," Oak Ridge National Laboratory Report NUREG/CR-1789, ORNL/NUREG/TM-399, March 1981 .

28. C.J. Hsu, P.G. Kroeger, and J. Colman, "The Effect of Prior Forced Circulation Coolings on the Thermohydraulics of an HTGR Primary Loop During Core Heat-Up Accidents," BNL (Informa1) Report BNL-NUREG-32520, Nov . 1982.

29. J.E. Meyer, "Hydrodynamic Models for the Treatment of Reactor Thermal Transients," Nuc1. Sci. Eng. 10, 269, 1961 .

30. G. Melese and R. Katz, Thermal and Flow Design of Helium-Cooled Reactors, American Nuclear Society, LaGrange Park, IL, 1984.

31. FSV-SAR

32. GASSAR

33. Sicherheitsstudie fuer HTR-Konzepte unter deutschen Standortbedingungen, Phase I B, Fachband III: Lecks im Primarkreislauf, Institut fur Nukleare Sicherheitsforschung, Kernforschungsanlage Juelich GmbH, Juel-Spez136/Bd.4, Mai 1982

34. Rainer Moormann, "Graphite Oxidation Phenomena During Massive Air Ingress Accidents in Nuclear High Temperature Gas Cooled Reactors with Pebble Bed Core," Ber. Bunsenges, Phys. Chem. 87, 1086-1900 (1983).

35. Rahim Nabbi, et a1., "Safety Analysis of the Reactivity Transients Resulting from Water Ingress into a High-Temperature Pebble Bed Reactor," Nuclear Technology, Vol. 62, Pf 172, August 1983.

36. M.B. Peroomian, A.W. Barsell, and J.C. Saeger, "OXIDE-3: A Computer Code for Analysis of HTGR Steam or Air Ingress Accidents," General Atomic Company, GA-A12493 (GA-LTR-7), January 1974.

37. A.W. BarselI and M.B. Peroomian, "Consequences of Water Ingress into the HTGR Primary Coolant." General Atomic Company, GA-A13171, Apri1 1975.

38. R. Moormann, and K. Petersen, "REACT/THERMIX Ein Computercode zur Berechnung der Stoerfallbedingten Graphitkorrosion in Kugelhaufenreaktoren," Kernforschungsanlage Juelich GmbH, Jue1-1782, Apri1 1982.

39. J. Skalyo, Jr., L.G. Epel and C. Sastre, "An Analysis of the Methods Utilized in OXIDE-3," Brookhaven National Laboratory Report, BNL-NUREG50810, April 1978.

40. W. Katscher, and R. Moormann, "Graphitkorrosion im HTG-Kugelhaufen bei Lufteinbruchstoerfallen und ihre Beeinflussung durch Kombination mit Wassereinbruch," DTG-Fachseminar "Chemie des Hochtemperaturreaktors"; JuelConf -43 , S. 43-52, Juelich (1981). 
41. M. Rossberg, and E. Wicke, "Transportvorgange und Oberflaechenreaktionen bei der Verbrennung Graphitischen Kohlenstoffs, Chemie-Ing.-Techn. 28, $181,(1956)$.

42. R. Moormann, and K. Schultes, "Erfullt das Nachwarmeabfuhrsystem des PNP500 die Anforderungen aus der Sicht der Graphitkorrosion bei Wasser und Lufteinbruchstoerfallen," Jahrestagung Kerntechnik '81, Proc. S. 199-202, Dusseldorf (1981).

43. R. Moormann, et a1., "Untersuchungen zur Graphitkorrosion bei Lufteinbruch in den Kugelhaufen-HTR," Jahrestagung Kerntechnik '80, Proc. S. 211-14, Ber1in (1980).

44. R. Moormann, et al., "Verhalten des HTR-Kugelhaufens bei Massivem Lufteinbruch," ATOMKERNENERGIE/KERNTECHNIK 35, 270-74, (1980).

45. C. Velasquez, et a1., "The Oxidation of 1451 Graphite by Steam," General Atomic Company GA-A-14951, August 1978.

46. R.G. Guido, A. Koestel, "Containment Condensing Heat Transfer," Thermal Hydraulics of Nuclear Reactors, Second International Topical Meeting on Nuclear Reactor Thermal Hydraulics, ANS pg. 1111, January 1983.

47. N. Corradini, "Turbulent Condensation on a Cold Wall in the Presence of a Noncondensible Gas," Thermal Hydraulics of Nuclear Reactors, Second International Topical Meeting on Nuclear Reactor Thermal Hydraulics, ANS pg. 1102, January 1983. 


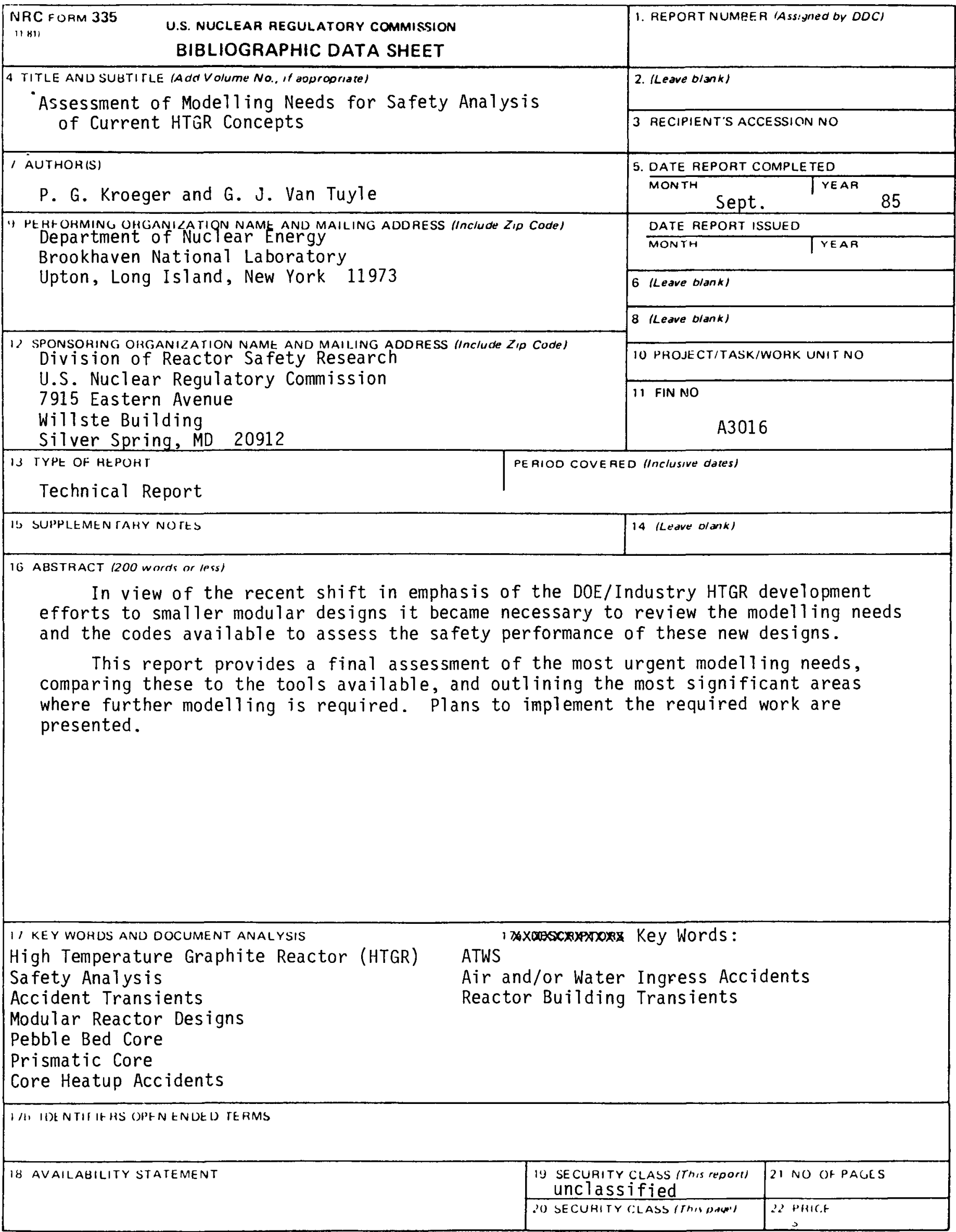

